\title{
Transcriptomic analysis of male and female Schistosoma mekongi adult worms
}

\author{
Orawan Phuphisut ${ }^{1}$, Pravech Ajawatanawong ${ }^{2}$, Yanin Limpanont ${ }^{3}$, Onrapak Reamtong ${ }^{4}$, Supaporn Nuamtanong ${ }^{1}$, \\ Sumate Ampawong ${ }^{5}$, Salisa Chaimon ${ }^{1}$, Paron Dekumyoy ${ }^{1}$, Dorn Watthanakulpanich ${ }^{1}$, Brett E. Swierczewski ${ }^{6}$ \\ and Poom Adisakwattana ${ }^{1 *}$
}

\begin{abstract}
Background: Schistosoma mekongi is one of five major causative agents of human schistosomiasis and is endemic to communities along the Mekong River in southern Lao People's Democratic Republic (Laos) and northern Cambodia. Sporadic cases of schistosomiasis have been reported in travelers and immigrants who have visited endemic areas. Schistosoma mekongi biology and molecular biology is poorly understood, and few S. mekongi gene and transcript sequences are available in public databases.

Results: Transcriptome sequencing (RNA-Seq) of male and female S. mekongi adult worms (a total of three biological replicates for each sex) were analyzed and the results demonstrated that approximately 304.9 and 363.3 million highquality clean reads with quality Q30 (> 90\%) were obtained from male and female adult worms, respectively. A total of 119,604 contigs were assembled with an average length of 1273 nt and an N50 of 2017 nt. From the contigs, 20,798 annotated protein sequences and 48,256 annotated transcript sequences were obtained using BLASTP and BLASTX searches against the UniProt Trematoda database. A total of 4658 and 3509 transcripts were predominantly expressed in male and female worms, respectively. Male-biased transcripts were mostly involved in structural organization while female-biased transcripts were typically involved in cell differentiation and egg production. Interestingly, pathway enrichment analysis suggested that genes involved in the phosphatidylinositol signaling pathway may play important roles in the cellular processes and reproductive systems of $S$. mekongi worms.
\end{abstract}

Conclusions: We present comparative transcriptomic analyses of male and female S. mekongi adult worms, which provide a global view of the S. mekongi transcriptome as well as insights into differentially-expressed genes associated with each sex. This work provides valuable information and sequence resources for future studies of gene function and for ongoing whole genome sequencing efforts in S. mekongi.

Keywords: Schistosoma mekongi, Transcriptome, Differentially-expressed genes, Gene expression, RNA-Seq

\section{Background}

Mekong schistosomiasis is an important human parasitic disease and is caused by infection with Schistosoma mekongi. The parasite is highly prevalent along the Mekong River in southern Lao People's Democratic Republic (Laos) and northern Cambodia [1-3]. Individuals infected by $S$. mekongi are mostly villagers living in endemic areas, but cases also occur in immigrants who resettle in other countries. Moreover, S. mekongi has

\footnotetext{
*Correspondence: poom.adi@mahidol.ac.th

'Department of Helminthology, Faculty of Tropical Medicine, Mahidol

University, Bangkok, Thailand

Full list of author information is available at the end of the article
}

been identified in international travelers who visited endemic areas, making this infection an important travel medicine issue in Southeast Asia [4-6].

As with other schistosome infections, disease develops after free-swimming S. mekongi larvae (cercariae) are released from a snail intermediate host, Neotricula aperta, and penetrate the human skin during swimming, bathing, farming and fishing [7]. Infection with S. mekongi is associated with a chronic local inflammatory response when eggs become entrapped in host tissues, resulting in intestinal disease, hepatosplenic inflammation and liver fibrosis [8]. No effective vaccine against $S$. mekongi is available, and anthelmintic treatment relies upon a single drug,

(c) The Author(s). 2018 Open Access This article is distributed under the terms of the Creative Commons Attribution 4.0 International License (http://creativecommons.org/licenses/by/4.0/), which permits unrestricted use, distribution, and 
praziquantel, against which resistance is becoming occurrence in some areas [9-13]. Thus, identification of novel targets for drug and vaccine development is urgently needed [14].

In previous studies, transcriptomic analyses of schistosomes have been conducted using expressed sequence tags (ESTs) [15-19], microarray hybridization [20-24] and serial analysis of gene expression [25-27]. However, data obtained using these technologies have limitations, including low throughput, short sequence length and resulting in challenges in assembly and the ability to analyze only known sequences. Recently, next-generation sequencing (NGS) technologies have significantly accelerated research in genomics, transcriptomics, epigenomics and metagenomics [28], which has dramatically improved the efficiency of gene discovery and gene expression analysis (RNA-Seq) in diverse species of plants and animals [29-33]. Transcriptomic analyses of human and animal schistosomes including S. mansoni, S. japonicum, S. haematobium and $S$. turkestanicum have been performed using RNA-Seq technology [34-43] and have contributed significantly to systematic efforts to identify gene targets. Despite recent advances in sequencing technology and bioinformatic methods, there is little information on the complete transcriptome of S. mekongi. Here, RNA-Seq technology and de novo assembly were used to provide a global view of the transcriptomes of male and female $S$. mekongi adult worms. The aim of our study was to produce transcriptomic data that would enhance our understanding of the biology of $S$. mekongi and facilitate the identification of candidate drug and vaccine targets.

\section{Results}

\section{RNA-Seq and de novo transcriptome assembly}

RNA-Seq analysis of $S$. mekongi adult worms using Illumina PE sequencing technology yielded a total of 346,331,720 and 411,906,616 raw reads from male and female worms, respectively. After quality assessment and trimming, 304,934,770 and 363,296,510 clean reads were obtained from male and female worms, respectively. Per-base quality distributions for each biological replicate are shown in Additional file 1: Figure S1.

Clean reads longer than $200 \mathrm{nt}$ were used for de novo assembly. A total of 190,741 and 190,922 contigs with N50 values of 1844 and 1965 nt were generated from assemblies with k-mer sizes 25 and 31, respectively. The assembly with $\mathrm{k}$-mer size 31 was subsequently selected, due to its high realignment rate and higher N50 value, to filter redundant sequences. Summaries of both transcriptome assemblies' quality and realignment rate are shown in Additional file 2: Table S1. A total of 119,604 contigs were obtained in the final assembly with an average contig length of $1273 \mathrm{nt}$. The shortest contig was $201 \mathrm{nt}$ long, while the longest contig was 30,465 nt long.
The N50 length of the final assembly was 2107 nt. A total of 42,600 contigs were longer than $1 \mathrm{~kb}$ and 625 contigs were longer than $10 \mathrm{~kb}$. The overall GC content was $34.1 \%$ (Table 1 ).

\section{Functional annotation and GO classification}

To annotate protein function, all 119,604 assembled contigs were subjected to prediction of protein CDS regions (Table 2). A total of 20,798 putative proteins were identified of which 19,744 could be annotated after BLASTP searching against the UniProt Trematoda database with an $E$-value cut-off $<10^{-5}$. Transcripts for which CDS regions could not be predicted were alternatively annotated using a BLASTX sequence similarity search against the UniProt Trematoda database with an $E$-value cut-off $<10^{-5}$. Following this analysis, 48,256 additional contigs could be assigned to functional proteins. All annotated transcripts produced from both analyses were further annotated using the GO databases of BLAST and Pfam. A total of 21,833 and 8462 assembled contigs were assigned to at least one of three GO terms of the BLAST and Pfam databases, respectively. GO assignments were grouped into three different categories: biological processes,

Table 1 Statistical summary of de novo assembled transcriptome sequences from male and female S. mekongi adult worms

\begin{tabular}{|c|c|c|}
\hline Parameter & Male worms & Female worms \\
\hline \multicolumn{3}{|c|}{ Summary of raw sequencing reads } \\
\hline Total raw reads ${ }^{a}$ & $346,331,720$ & $411,906,616$ \\
\hline $\begin{array}{l}\text { Total raw read } \\
\text { nucleotides } \\
\text { above Q30 (\%) }\end{array}$ & $\begin{array}{l}48,771,315,768 \\
(93.9 \%)\end{array}$ & $\begin{array}{l}57,423,179,186 \\
(92.9 \%)\end{array}$ \\
\hline \multicolumn{3}{|c|}{ Summary of trimmed sequencing reads } \\
\hline Total clean reads ${ }^{\mathrm{a}}$ & $304,934,770$ & $363,296,510$ \\
\hline $\begin{array}{l}\text { Total clean read } \\
\text { nucleotides } \\
\text { above Q30 (\%) }\end{array}$ & $\begin{array}{l}43,463,738,987 \\
(97.4 \%)\end{array}$ & $\begin{array}{l}51,257,988,579 \\
(96.9 \%)\end{array}$ \\
\hline \multicolumn{3}{|c|}{ Summary of final transcriptome assembly contigs } \\
\hline Number of contigs & 119,604 & \\
\hline $\begin{array}{l}\text { Smallest contig } \\
\text { length (nt) }\end{array}$ & 201 & \\
\hline $\begin{array}{l}\text { Largest contig } \\
\text { length (nt) }\end{array}$ & 30,465 & \\
\hline $\begin{array}{l}\text { Number of contigs } \\
\text { with length }<200 \mathrm{nt}\end{array}$ & 0 & \\
\hline $\begin{array}{l}\text { Number of contigs } \\
\text { with length }>1 \mathrm{k} n t\end{array}$ & 42,600 & \\
\hline $\begin{array}{l}\text { Number of contigs } \\
\text { with length }>10 \mathrm{knt}\end{array}$ & 625 & \\
\hline N50 (nt) & 2107 & \\
\hline GC content (\%) & 34.1 & \\
\hline
\end{tabular}

${ }^{\mathrm{a}}$ Reads of three replicates 
Table 2 Summary of assembled transcript annotation

\begin{tabular}{ll}
\hline Transcript annotation & No. of transcripts \\
\hline Total transcripts & 119,604 \\
Total protein sequences & 20,798 \\
$\begin{array}{l}\text { Number of protein sequences } \\
\text { with BLASTP hits }\end{array}$ & 19,744 \\
$\begin{array}{l}\text { Number of transcript sequences } \\
\text { with BLASTX hits }\end{array}$ & 48,256 \\
$\begin{array}{l}\text { Number of transcript sequences } \\
\text { with GO terms (BLAST) }\end{array}$ & 21,833 \\
$\begin{array}{l}\text { Number of transcript sequences } \\
\text { with GO terms (Pfam) }\end{array}$ & 8462 \\
\hline
\end{tabular}

molecular functions and cellular components, containing $8694,16,366$ and 11,055 transcripts, respectively.

\section{Analysis of differential expression}

Of 119,604 total transcripts, 18,643 were DE in male and female adult worms with cpm > 1 (Fig. 1). In total, 8169 transcripts were significantly DE between male and female worms (FDR value $<0.05$ and fold change $>2.0$ ), spanning a $\log _{2}$ fold change range of -18.5 to 16.2 . The red spots shown in Fig. 1 represent DE transcripts. Among all significantly DE transcripts, 4659 and 3510 transcripts were upregulated in male and female worms, respectively. The functional annotations of DE transcripts demonstrated that 2391 transcripts upregulated in male worms could be annotated but 2268 transcripts had unknown functions, while 1308 transcripts upregulated in

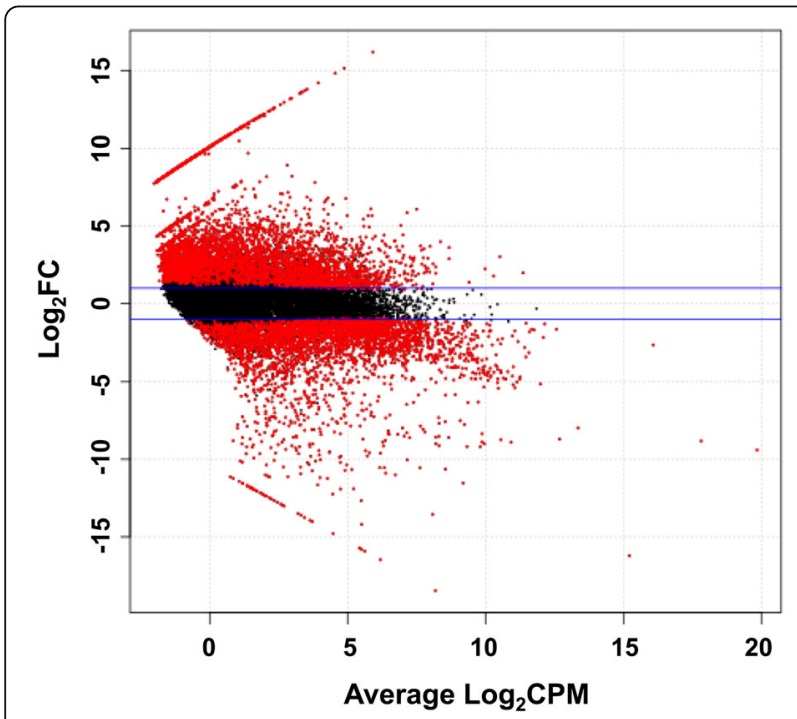

Fig. 1 Smear plot of all DE transcripts with cpm > 1.0 from S. mekongi male and female worms. The graph shows average $\log _{2}(\mathrm{cpm})$ on the $x$-axis vs $\log _{2}$ (fold change in gene expression) between male and female worms on the $y$-axis. DE transcripts are shown in red and non-DE transcripts are shown in black female worms could be annotated but 2202 transcripts had unknown functions.

The 50 most significantly DE transcripts of both male and female worms were shown in a heatmap (Fig. 2), with11 and 39 of these transcripts being significantly upregulated in male and female worms, respectively. However, 22 of these transcripts had unknown functions (4 and 18 transcripts in male and female worms, respectively). Transcript identification and protein descriptions are listed in Additional file 3: Table S2.

Among the significantly upregulated transcripts for each sex, the 50 transcripts with the highest upregulation are listed in Tables 3 and 4. In male worms, these were transcripts related to cytoskeleton-, motor-, and neuronal-associated proteins (dynein, tropomyosin 2, myosin light chain kinase and plexin A1) and to cell adhesion (integrin, CD97 antigen and serine-rich adhesin for platelets). Several transcripts associated with signaling pathways were also upregulated in male worms including serine/threonine kinase, receptor protein-tyrosine kinase, putative multiple ankyrin repeats single $\mathrm{KH}$ domain protein, serine/threonine-protein kinase PAK 3, rapamycin-insensitive companion of mTOR and regulator of G-protein signaling 3 (Table 3).

Among the 50 most upregulated transcripts in female worms, transcripts with known function primarily related to glycosylation activity (O-glycosyltransferase, mannosyltransferase), peptidase activity (elastase $2 \mathrm{~b}$ ) and antioxidant enzyme activity (thioredoxin domain-containing protein 4). Moreover, several genes related to DNA- and protein-misfolding repair activity (scythe/bat3, DNA excision repair protein ERCC-6, 26S proteasome non-ATPase regulatory subunit 11), gene regulation activity (Ccr4-not transcription complex) and cellular and physiological control activity (inositol 1,4,5-trisphosphate receptor) were upregulated (Table 4).

\section{GO and KEGG pathway analyses of DE transcripts}

According to the GO classification of DE transcripts, there were 2916, 14,141 and 6693 transcripts assigned to biological process, cellular component and molecular function categories, respectively, of which 1627, 7461 and 3963 transcripts were significantly DE (FDR value $<0.05$ ) (Additional file 4: Table S3). The top three predominant terms for 'biological process' were cell communication, signaling, and single organism signaling; for 'cellular component' they were membrane, membrane part, and intrinsic component of membrane; and for 'molecular function' they were transporter activity, transmembrane transporter activity and substrate-specific transporter activity (Fig. 3a-c).

Furthermore, significant GO terms in each sex was analyzed and demonstrated that the male upregulated transcripts composed of cell communication, single organism signaling and signaling were the top three significant GO terms for 'biological process', intrinsic component 


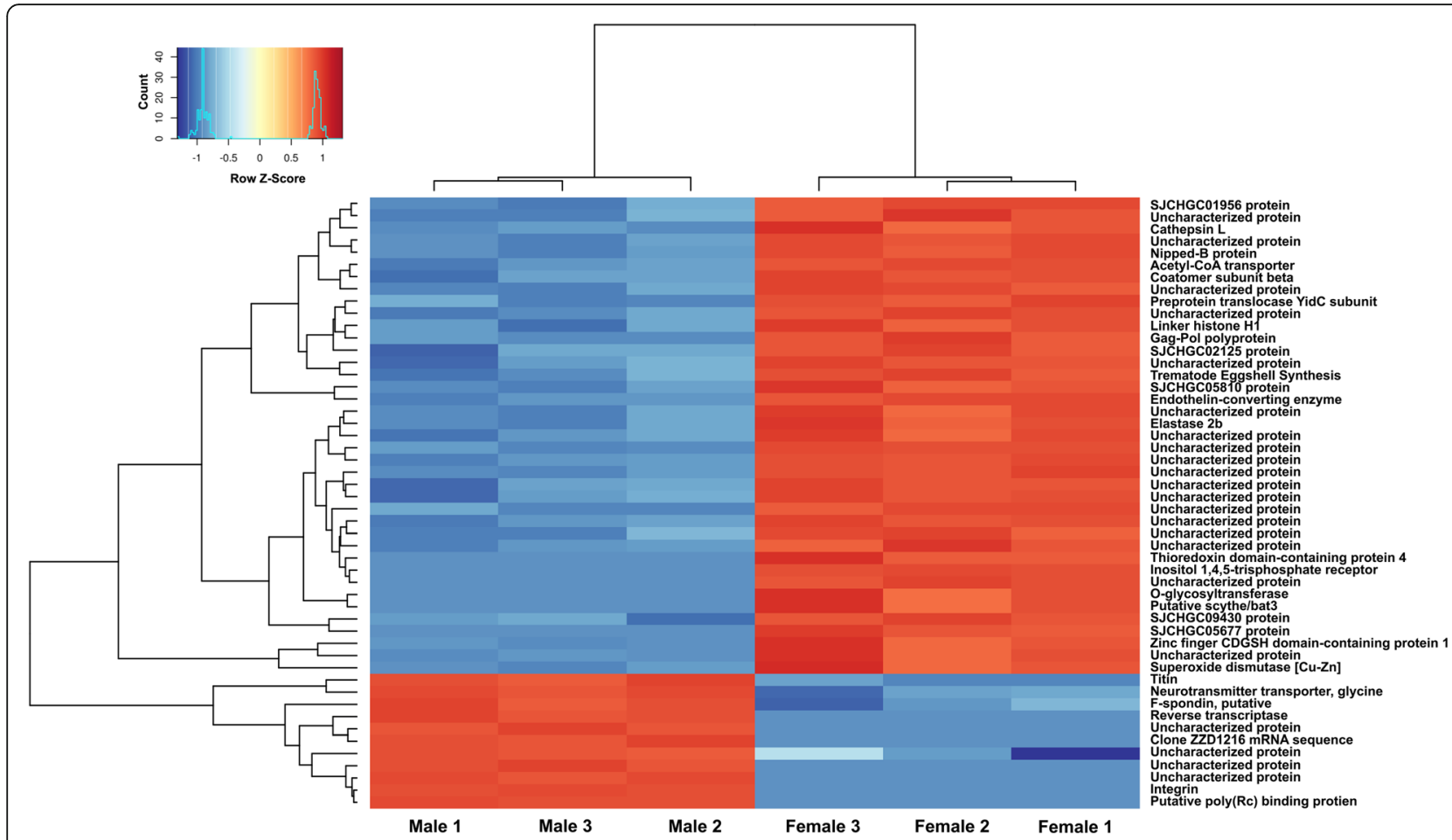

Fig. 2 Heatmap of 50 most significantly DE transcripts from S. mekongi male vs female worms with three biological replicates. DE transcripts with higher expression levels are shown in red. DE transcripts with lower expression levels are shown in blue

of membrane, integral component of membrane and plasma membrane were significant GO terms for 'cellular component', signal transducer activity, receptor activity and molecular transducer activity were significant GO terms for 'molecular function' (Additional file 5: Table S4 and Additional file 6: Figure S2). While, significant GO terms in female upregulated transcripts revealed that cellular amide metabolic process, peptide metabolic process, and amide biosynthetic process were significant GO terms for 'biological process', intracellular ribonucleoprotein complex, ribonucleoprotein complex and ribosome were significant GO terms for 'cellular component', structural constituent of ribosome, structural molecule activity, and RNA binding were significant GO terms for 'molecular function' (Additional file 7: Table S5, Additional file 8: Figure S3).

KEGG pathway enrichment analysis revealed that a total of 122 pathways were significantly enriched comparing male $v s$ female worms (FDR value $<0.05$ ) (Additional file 9: Table S6). These pathways were composed of 397 DE transcripts distributed among the following classes: organismal systems (29.5\%), human disease (22.7\%), environmental Information processing (17.3\%), cellular processes (17.3\%), genetic information processing (7.4\%) and metabolism (5.7\%). The enrichment pathway analysis suggested that the top three sub-classes were composed of transcripts relating to signal transduction (17.3\%), endocrine system (9.8\%) and cell growth and death (7.8\%) (Fig. 4). Analysis of the top 30 most significantly enriched pathways showed that the phosphatidylinositol signaling system was the most significantly enriched pathway $(P=4.28 \mathrm{E} 10-09)$, followed by cell cycle yeast $(P=3.52 \mathrm{E}-09)$, meiosis - yeast $(P=3.93 \mathrm{E}-09)$, cell cycle $(P=1.92 \mathrm{E}-08)$ and focal adhesion pathways $(P=1.02 \mathrm{E}-07)$ (Fig. 5). Upregulated transcripts involved in the phosphatidylinositol signaling system are shown in Fig. 6 and Additional file 10: Table S7.

The significant KEGG pathway in each sex demonstrated that the top three significant KEGG pathways in the male worm comprised of focal adhesion, axon guidance and phosphatidylinositol signaling system, respectively. While, cell cycle - yeast, meiosis - yeast and cell cycle were top three significant KEGG pathways in female worms (Additional file 11: Table S8).

\section{RT-qPCR validation}

Thirty representative transcripts (10 upregulated in male worms, 10 upregulated in female worm and 10 non-DE transcripts) were randomly selected for validation of the RNA-Seq analysis using RT-qPCR. The expression of these genes in male and female worms was validated by RT-qPCR, which was highly correlated with the results obtained by RNA-Seq (10 upregulated transcripts in male worms, $r=0.793, P=0.006 ; 10$ upregulated transcripts in female worms, $r=0.98, P<0.000001$; non-DE transcripts, $r=0.98, P<0.000001$ (Additional file 12: Figure S4). 
Table 3 Top 50 most significantly upregulated transcripts in S. mekongi male worms

\begin{tabular}{|c|c|c|c|c|c|}
\hline Transcript ID & Protein description & $\log _{2}(F C)$ & $P$-value & FDR & Pfam annotation \\
\hline comp65_seq18 & Reverse transcriptase & 16.2 & $2.66 \mathrm{E}-92$ & $1.24 \mathrm{E}-88$ & - \\
\hline comp2831_seq1 & Uncharacterized protein & 15.2 & 1.47E-70 & $2.29 \mathrm{E}-67$ & - \\
\hline comp1481_seq2 & $\begin{array}{l}\text { Clone ZZD1216 mRNA } \\
\text { sequence }\end{array}$ & 14.8 & 1.19E-70 & 2.01E-67 & - \\
\hline comp926_seq0 & Uncharacterized protein & 14.2 & $3.84 \mathrm{E}-56$ & $3.01 \mathrm{E}-53$ & - \\
\hline comp2062_seq0 & Uncharacterized protein & 13.8 & $1.53 \mathrm{E}-45$ & $6.63 \mathrm{E}-43$ & - \\
\hline comp4508_seq0 & Integrin & 13.7 & $2.79 \mathrm{E}-47$ & 1.30E-44 & - \\
\hline comp4099_seq6 & Uncharacterized protein & 13.6 & $3.96 \mathrm{E}-41$ & $1.34 \mathrm{E}-38$ & $\begin{array}{l}\text { G-patch domain, FtsJ-like } \\
\text { methyltransferase }\end{array}$ \\
\hline comp556_seq2 & Hypothetical protein & 13.6 & $3.35 \mathrm{E}-32$ & 4.84E-30 & - \\
\hline comp4395_seq2 & $\begin{array}{l}\text { Putative poly(Rc) binding } \\
\text { protein }\end{array}$ & 13.6 & $1.45 \mathrm{E}-43$ & $5.73 \mathrm{E}-41$ & $\mathrm{KH}$ domain \\
\hline comp298_seq2 & Uncharacterized protein & 13.5 & $2.02 \mathrm{E}-41$ & 7.11E-39 & Ankyrin repeats \\
\hline comp5387_seq1 & Serine/threonine kinase & 13.2 & $1.95 \mathrm{E}-36$ & 4.39E-34 & $\begin{array}{l}\text { Protein kinase domain, } \\
\text { protein tyrosine kinase }\end{array}$ \\
\hline comp3544_seq2 & Dynein-associated protein & 13.2 & $1.51 \mathrm{E}-34$ & $2.79 \mathrm{E}-32$ & - \\
\hline comp510_seq4 & Tropomyosin-2 & 13.0 & $1.04 \mathrm{E}-22$ & $6.12 \mathrm{E}-21$ & $\begin{array}{l}\text { Aida N-terminus, } \\
\text { tropomyosin }\end{array}$ \\
\hline comp1917_seq1 & Lysine-tRNA ligase & 12.8 & $2.43 \mathrm{E}-26$ & $2.02 \mathrm{E}-24$ & $\begin{array}{l}\text { tRNA anti-codon, OB-fold } \\
\text { nucleic acid binding domain }\end{array}$ \\
\hline comp7221_seq1 & Uncharacterized protein & 12.6 & $3.04 \mathrm{E}-27$ & $2.75 \mathrm{E}-25$ & - \\
\hline comp8398_seq0 & Putative homeobox protein & 12.6 & $6.23 \mathrm{E}-25$ & $4.54 \mathrm{E}-23$ & $\begin{array}{l}\text { N-terminal of Homeobox } \\
\text { Meis and PKNOX1 }\end{array}$ \\
\hline comp3445_seq0 & $\begin{array}{l}\text { Receptor protein-tyrosine } \\
\text { kinase }\end{array}$ & 12.6 & $1.84 \mathrm{E}-26$ & $1.55 \mathrm{E}-24$ & $\begin{array}{l}\text { Receptor } L \text { domain, furin-like } \\
\text { cysteine rich region }\end{array}$ \\
\hline comp3797_seq0 & Uncharacterized protein & 12.5 & $2.10 \mathrm{E}-26$ & $1.75 \mathrm{E}-24$ & BTG family \\
\hline comp3182_seq1 & $\begin{array}{l}\text { Putative multiple ankyrin } \\
\text { repeats single KH domain } \\
\text { protein }\end{array}$ & 12.4 & $2.95 \mathrm{E}-17$ & $9.84 \mathrm{E}-16$ & Ankyrin repeats \\
\hline comp115_seq0 & Uncharacterized protein & 12.4 & 1.44E-22 & 8.37E-21 & $\begin{array}{l}\text { Arrestin (or S-antigen), } \\
\mathrm{N} \text {-terminal domain }\end{array}$ \\
\hline comp7837_seq2 & Uncharacterized protein & 12.2 & $8.70 \mathrm{E}-24$ & $5.69 \mathrm{E}-22$ & Cadherin domain \\
\hline comp5447_seq1 & $\begin{array}{l}\text { Myosin light chain kinase, } \\
\text { smooth muscle }\end{array}$ & 12.2 & 1.17E-15 & $3.10 \mathrm{E}-14$ & $\begin{array}{l}\text { Immunoglobulin } \\
\text { I-set domain }\end{array}$ \\
\hline comp3754_seq1 & $\begin{array}{l}\text { Metastasis suppressor } \\
\text { protein } 1\end{array}$ & 12.1 & $3.29 \mathrm{E}-19$ & $1.38 \mathrm{E}-17$ & $\begin{array}{l}\text { IRSp53/MIM homology } \\
\text { domain }\end{array}$ \\
\hline comp8738_seq10 & Uncharacterized protein & 12.1 & $2.30 \mathrm{E}-21$ & $1.20 \mathrm{E}-19$ & - \\
\hline comp4029_seq0 & Plexin-A1 & 12.1 & 4.14E-20 & $1.88 \mathrm{E}-18$ & $\begin{array}{l}\text { Plexin repeat, IPT/TIG } \\
\text { domain }\end{array}$ \\
\hline comp138_seq8 & SJCHGC08958 protein & 12.0 & $1.54 \mathrm{E}-13$ & $3.00 \mathrm{E}-12$ & $\begin{array}{l}\text { Trematode eggshell } \\
\text { synthesis protein }\end{array}$ \\
\hline comp5826_seq0 & Uncharacterized protein & 12.0 & $2.10 \mathrm{E}-22$ & 1.19E-20 & Leucine rich repeat \\
\hline comp3044_seq3 & Uncharacterized protein & 12.0 & $1.01 \mathrm{E}-20$ & 4.89E-19 & $\begin{array}{l}\text { NIF3 (NGG1p interacting } \\
\text { factor 3) }\end{array}$ \\
\hline comp8147_seq2 & Uncharacterized protein & 11.9 & 4.28E-20 & $1.94 \mathrm{E}-18$ & Laminin G domain \\
\hline comp595_seq0 & $\begin{array}{l}\text { Choline dehydrogenase, } \\
\text { mitochondrial }\end{array}$ & 11.9 & 7.87E-15 & 1.85E-13 & GMC oxidoreductase \\
\hline comp1402_seq1 & Uncharacterized protein & 11.9 & $1.25 \mathrm{E}-16$ & $3.78 \mathrm{E}-15$ & - \\
\hline comp490_seq3 & Serine/threonine-protein & 11.9 & 5.01E-19 & 2.07E-17 & P21-Rho-binding domain \\
\hline
\end{tabular}


Table 3 Top 50 most significantly upregulated transcripts in S. mekongi male worms (Continued)

\begin{tabular}{|c|c|c|c|c|c|}
\hline Transcript ID & Protein description & $\log _{2}(F C)$ & $P$-value & FDR & Pfam annotation \\
\hline comp8255_seq1 & Uncharacterized protein & 11.8 & $3.00 \mathrm{E}-20$ & $1.38 \mathrm{E}-18$ & - \\
\hline comp4371_seq0 & Putative $A B C$ transporter & 11.8 & $1.63 \mathrm{E}-19$ & 7.01E-18 & $\mathrm{ABC}$ transporter \\
\hline comp5811_seq8 & $\begin{array}{l}\text { Rapamycin-insensitive } \\
\text { companion of mTOR }\end{array}$ & 11.8 & $2.32 \mathrm{E}-17$ & $7.85 \mathrm{E}-16$ & $\begin{array}{l}\text { Rapamycin-insensitive } \\
\text { companion of mTOR, } \\
\text { domain } 5\end{array}$ \\
\hline comp9143_seq1 & $\begin{array}{l}\text { Regulator of G-protein } \\
\text { signaling } 3\end{array}$ & 11.8 & $5.29 \mathrm{E}-21$ & $2.64 \mathrm{E}-19$ & $\begin{array}{l}\text { C2 domain, PDZ domain } \\
\text { (DHR or GLGF) }\end{array}$ \\
\hline comp9843_seq1 & Uncharacterized protein & 11.8 & $6.13 \mathrm{E}-20$ & $2.71 \mathrm{E}-18$ & Rhodopsin family \\
\hline comp8166_seq1 & Uncharacterized protein & 11.8 & $4.38 \mathrm{E}-21$ & 2.20E-19 & - \\
\hline comp1561_seq0 & Uncharacterized protein & 11.6 & $2.16 \mathrm{E}-12$ & $3.55 \mathrm{E}-11$ & - \\
\hline comp6197_seq1 & Uncharacterized protein & 11.6 & $3.52 \mathrm{E}-17$ & 1.17E-15 & - \\
\hline comp9531_seq0 & Putative ankyrin 2,3/unc44 & 11.6 & 2.07E-16 & $6.05 \mathrm{E}-15$ & Ankyrin repeats \\
\hline comp9039_seq1 & $\begin{array}{l}\text { Centrosomal protein } \\
\text { of } 120 \mathrm{kDa}\end{array}$ & 11.6 & 2.64E-19 & $1.11 \mathrm{E}-17$ & C2 domain, Cep120 protein \\
\hline comp2906_seq3 & CD97 antigen & 11.6 & $3.96 \mathrm{E}-18$ & $1.47 \mathrm{E}-16$ & Secretin family \\
\hline comp3517_seq2 & $\begin{array}{l}\text { Rho guanine nucleotide } \\
\text { exchange factor } 12\end{array}$ & 11.6 & $1.38 \mathrm{E}-19$ & $6.00 \mathrm{E}-18$ & $\begin{array}{l}\text { Regulator of G protein } \\
\text { signalling-like domain }\end{array}$ \\
\hline comp2195_seq3 & Uncharacterized protein & 11.6 & $1.91 \mathrm{E}-15$ & 4.93E-14 & Galactoside-binding lectin \\
\hline comp5487_seq0 & $\begin{array}{l}\text { Uncharacterized protein } \\
\text { C7orf63-like protein }\end{array}$ & 11.6 & $8.05 E-20$ & $3.52 \mathrm{E}-18$ & - \\
\hline comp4205_seq4 & $\begin{array}{l}\text { Serine-rich adhesin for } \\
\text { platelets }\end{array}$ & 11.5 & $2.14 \mathrm{E}-14$ & $4.76 \mathrm{E}-13$ & - \\
\hline comp3759_seq1 & $\begin{array}{l}\text { Putative Alstrom syndrome } \\
\text { protein }\end{array}$ & 11.5 & $1.86 \mathrm{E}-16$ & $5.50 \mathrm{E}-15$ & - \\
\hline comp9022_seq1 & Uncharacterized protein & 11.5 & 1.97E-18 & 7.61E-17 & MORN repeat \\
\hline comp10754_seq0 & Uncharacterized protein & 11.4 & 8.21E-19 & 3.31E-17 & Cadherin-like \\
\hline
\end{tabular}

\section{Discussion}

Mekong schistosomiasis caused by $S$. mekongi remains a health problem in both humans and animals resident in endemic areas [44-46]. Moreover, Mekong schistosomiasis has sporadically emerged throughout the world due to immigration, travel and animal trading [4-7]. To prevent and control this infection, several strategies have been implemented including mass administration of praziquantel in human and reservoir animals, rapid diagnosis to identify asymptomatic cases, snail control and health education. These interventions showed variable results (both successful and unsuccessful) in each area [47]. Thus, novel prevention and control strategies need to be developed based on basic and applied S. mekongi biology, especially genomic, transcriptomic and proteomic analyses. However, public databases contain few $S$. mekongi sequences. Herein, we provide the first transcriptomic database of $S$. mekongi adult worms, and compared gene expression between male and female adult parasites.

In this study, RNA-Seq of $S$. mekongi was performed using the Illumina $\mathrm{PE}$ sequencing platform with a read length of 150 bases. De novo assembly was carried out prior to annotation and downstream analysis. As there was no available reference genome, de novo assembly was required to generate contigs. In this regard, the de novo transcriptome assembler Bridger was selected as it provides the highest accuracy for paired end reads and the most complete reconstruction of transcripts compared to other assemblers [48].

After annotation, we demonstrated that 4659 and 3510 DE transcripts were significantly upregulated in adult male and female worms, respectively. Genes encoding cytoskeleton-, motor- and neuronal-associated proteins (dynein, tropomyosin 2, myosin light chain kinase and plexin A1) were predominantly upregulated in male worms. Our findings are consistent with previous studies of S. mansoni and S. japonicum [20, 21, 23, 49-51]. Upregulation of cytoskeleton and motor proteins in male worms may imply their role in the physical support of female worms to facilitate their migration against blood flow from hepatic portal sites to the smaller mesenteric circulation where they lay their eggs [24].

In addition, high expression of adhesion molecule, integrin, was observed in $S$. mekongi male worms. In $S$. mansoni, integrins were predominantly transcribed in reproductive tissue including testes, ovary, vitellarium 
Table 4 Top 50 most significantly upregulated transcripts in S. mekongi female worms

\begin{tabular}{|c|c|c|c|c|c|}
\hline Transcript ID & Protein description & $\log _{2}(\mathrm{FC})$ & $P$-value & FDR & Pfam annotation \\
\hline comp837_seq1 & SJCHGC05677 protein & 18.5 & $1.51 \mathrm{E}-88$ & $4.69 E-85$ & - \\
\hline comp546_seq10 & O-glycosyltransferase & 16.5 & $6.50 \mathrm{E}-54$ & 4.04E-51 & Tetratricopeptide repeat \\
\hline comp1_seq2 & Uncharacterized protein & 16.2 & $2.08 \mathrm{E}-09$ & $2.06 \mathrm{E}-08$ & - \\
\hline comp1141_seq3 & $\begin{array}{l}\text { Putative scythe/bat3 DNA } \\
\text { repair }\end{array}$ & 15.9 & 7.99E-51 & $4.51 \mathrm{E}-48$ & Ubiquitin family \\
\hline comp401_seq5 & SJCHGC09037 protein & 15.8 & 7.56E-34 & $1.29 \mathrm{E}-31$ & $\begin{array}{l}\text { Protein similar to CwfJ } \\
\text { C-terminus } 1\end{array}$ \\
\hline comp7058_seq0 & Uncharacterized protein & 15.7 & $6.12 \mathrm{E}-20$ & $2.71 \mathrm{E}-18$ & - \\
\hline comp524_seq5 & Uncharacterized protein & 14.8 & $8.48 \mathrm{E}-19$ & $3.41 \mathrm{E}-17$ & - \\
\hline comp5822_seq2 & $\begin{array}{l}\text { DNA excision repair protein } \\
\text { ERCC-6 DNA repair }\end{array}$ & 14.2 & $7.21 \mathrm{E}-29$ & $7.68 \mathrm{E}-27$ & $\begin{array}{l}\text { Type III restriction } \\
\text { enzyme, res subunit }\end{array}$ \\
\hline comp5430_seq10 & $\begin{array}{l}\text { Inositol 1,4,5-trisphosphate } \\
\text { receptor }\end{array}$ & 14.0 & $5.20 \mathrm{E}-88$ & $1.39 \mathrm{E}-84$ & $\begin{array}{l}\text { Inositol 1,4,5-trisphosphate/ } \\
\text { ryanodine receptor }\end{array}$ \\
\hline comp3416_seq1 & $\begin{array}{l}\text { Thioredoxin domain- } \\
\text { containingprotein } 4\end{array}$ & 13.9 & $1.32 \mathrm{E}-48$ & $7.02 \mathrm{E}-46$ & Thioredoxin-like domain \\
\hline comp3035_seq0 & Uncharacterized protein & 13.7 & $7.86 \mathrm{E}-27$ & $6.85 \mathrm{E}-25$ & DnaJ domain \\
\hline comp6618_seq1 & Uncharacterized protein & 13.6 & $3.75 \mathrm{E}-67$ & 4.99E-64 & - \\
\hline comp247_seq3 & SJCHGC09430 protein & 13.5 & $2.43 \mathrm{E}-64$ & $2.66 \mathrm{E}-61$ & - \\
\hline comp3544_seq3 & Mannosyltransferase & 13.5 & 4.23E-24 & $2.84 \mathrm{E}-22$ & $\begin{array}{l}\text { Alg9-like mannosyltransferase } \\
\text { family }\end{array}$ \\
\hline comp7684_seq1 & Uncharacterized protein & 13.0 & $2.85 \mathrm{E}-26$ & $2.34 \mathrm{E}-24$ & - \\
\hline comp1544_seq2 & $\begin{array}{l}\text { EH domain-binding } \\
\text { protein } 1\end{array}$ & 12.9 & $5.14 \mathrm{E}-22$ & $2.83 \mathrm{E}-20$ & CAMSAP CH domain \\
\hline comp4065_seq0 & Uncharacterized protein & 12.9 & 7.78E-31 & $1.00 \mathrm{E}-28$ & - \\
\hline comp3239_seq2 & Uncharacterized protein & 12.8 & $1.94 \mathrm{E}-19$ & $8.30 \mathrm{E}-18$ & $\begin{array}{l}\text { Phosphatidylethanolamine- } \\
\text { binding protein }\end{array}$ \\
\hline comp167028_seq0 & Uncharacterized protein & 12.7 & $2.33 \mathrm{E}-64$ & $2.66 \mathrm{E}-61$ & - \\
\hline comp7307_seq0 & Uncharacterized protein & 12.7 & 1.97E-31 & $2.68 \mathrm{E}-29$ & - \\
\hline comp6088_seq2 & Uncharacterized protein & 12.6 & 7.12E-39 & $1.92 \mathrm{E}-36$ & - \\
\hline comp4607_seq0 & Uncharacterized protein & 12.5 & $7.98 \mathrm{E}-33$ & $1.23 \mathrm{E}-30$ & - \\
\hline comp8587_seq1 & Pol polyprotein & 12.4 & $2.50 \mathrm{E}-40$ & $7.78 \mathrm{E}-38$ & - \\
\hline comp5229_seq0 & Uncharacterized protein & 12.3 & $4.78 \mathrm{E}-15$ & $1.16 \mathrm{E}-13$ & - \\
\hline comp8246_seq0 & Uncharacterized protein & 12.3 & 4.60E-25 & $3.41 \mathrm{E}-23$ & - \\
\hline comp2149_seq0 & Uncharacterized protein & 12.2 & 4.45E-97 & 2.77E-93 & - \\
\hline comp5198_seq1 & Uncharacterized protein & 12.2 & 1.16E-28 & $1.20 \mathrm{E}-26$ & - \\
\hline comp475_seq2 & $\begin{array}{l}\text { Ccr4-not transcription } \\
\text { complex gene regulation }\end{array}$ & 12.2 & $1.52 \mathrm{E}-37$ & $3.94 \mathrm{E}-35$ & - \\
\hline comp8567_seq0 & Uncharacterized protein & 12.0 & $1.58 \mathrm{E}-31$ & $2.17 \mathrm{E}-29$ & - \\
\hline comp7704_seq0 & Uncharacterized protein & 12.0 & $7.90 \mathrm{E}-28$ & $7.63 \mathrm{E}-26$ & - \\
\hline comp1502_seq0 & Uncharacterized protein & 12.0 & $3.49 \mathrm{E}-20$ & $1.59 \mathrm{E}-18$ & - \\
\hline comp9595_seq0 & Uncharacterized protein & 11.9 & 4.66E-30 & $5.57 \mathrm{E}-28$ & - \\
\hline comp29_seq2 & SJCHGC05410 protein & 11.9 & $1.22 \mathrm{E}-17$ & $4.25 \mathrm{E}-16$ & - \\
\hline comp5733_seq0 & Elastase $2 b$ & 11.9 & $5.02 \mathrm{E}-60$ & $4.92 \mathrm{E}-57$ & Trypsin-like peptidase domain \\
\hline comp785_seq0 & Uncharacterized protein & 11.9 & $1.50 \mathrm{E}-22$ & $8.68 \mathrm{E}-21$ & - \\
\hline comp11219_seq0 & Uncharacterized protein & 11.9 & $3.03 E-36$ & $6.57 \mathrm{E}-34$ & - \\
\hline comp9353_seq1 & Uncharacterized protein & 11.8 & 2.73E-21 & $1.40 \mathrm{E}-19$ & - \\
\hline comp969_seq7 & Uncharacterized protein & 11.8 & $6.68 \mathrm{E}-27$ & $5.93 \mathrm{E}-25$ & - \\
\hline
\end{tabular}


Table 4 Top 50 most significantly upregulated transcripts in S. mekongi female worms (Continued)

\begin{tabular}{|c|c|c|c|c|c|}
\hline Transcript ID & Protein description & $\log _{2}(F C)$ & $P$-value & FDR & Pfam annotation \\
\hline comp5698_seq0 & Uncharacterized protein & 11.8 & $1.13 \mathrm{E}-35$ & $2.34 \mathrm{E}-33$ & - \\
\hline comp10698_seq1 & Uncharacterized protein & 11.7 & $6.86 \mathrm{E}-34$ & $1.18 \mathrm{E}-31$ & - \\
\hline comp7614_seq1 & Uncharacterized protein & 11.7 & $2.55 \mathrm{E}-21$ & $1.32 \mathrm{E}-19$ & - \\
\hline comp4729_seq2 & Uncharacterized protein & 11.6 & 1.17E-30 & $1.45 \mathrm{E}-28$ & $\begin{array}{l}\text { Alpha amylase, catalytic } \\
\text { domain }\end{array}$ \\
\hline comp10183_seq1 & Uncharacterized protein & 11.5 & 1.90E-21 & $1.01 \mathrm{E}-19$ & - \\
\hline comp5834_seq0 & SJCHGC06880 protein & 11.5 & $2.91 \mathrm{E}-33$ & $4.68 \mathrm{E}-31$ & RING-variant domain \\
\hline comp268_seq0 & $\begin{array}{l}\text { Putative } 265 \text { proteasome } \\
\text { non-ATPase regulatory } \\
\text { subunit } 11 \text { protein } \\
\text { misfolding repair }\end{array}$ & 11.5 & $8.14 \mathrm{E}-05$ & $3.44 \mathrm{E}-4$ & $\mathrm{PCl}$ domain \\
\hline comp9969_seq1 & Uncharacterized protein & 11.4 & $2.39 \mathrm{E}-33$ & $3.87 \mathrm{E}-31$ & - \\
\hline comp1262_seq5 & Uncharacterized protein & 11.2 & 3.05E-22 & $1.70 \mathrm{E}-20$ & Dynein heavy chain \\
\hline comp1218_seq2 & $\begin{array}{l}\text { Connector enhancer of } \\
\text { kinase suppressor of Ras2 }\end{array}$ & 11.2 & 5.59E-30 & $6.52 \mathrm{E}-28$ & $\begin{array}{l}\text { PDZ domain } \\
\text { (DHR or GLGF) }\end{array}$ \\
\hline comp5896_seq0 & Uncharacterized protein & 11.2 & 5.53E-90 & $2.06 \mathrm{E}-86$ & - \\
\hline comp5214_seq0 & Uncharacterized protein & 11.1 & 2.20E-29 & $2.42 \mathrm{E}-27$ & - \\
\hline
\end{tabular}

and ootype. Downexpression of integrins using RNAi affected shape abnormality of oocyte. These indicate an indispensable role of integrin in reproductive processes of S. mansoni that may implied to other Schistosoma spp. and other Platyhelminthes [52, 53]. CD97 homolog is another adhesion molecule highly upregulated in $S$. mekongi male worms. CD97 is a member of adhesion G protein-coupled receptor expressed on the surface of hematopoietic stem cells, immune cells, smooth muscle, etc. The three known ligands interacting with CD97 have been identified and characterized including complement decay-accelerating factor (CD55), chondroitin sulfate and integrin $\alpha 5 \beta 1$ that they are the key molecules playing important roles in several biological and physiological processes in the cells [54]. However, basic function, property and tissue localization of CD97 in parasitic helminths and other pathogens are still unknown and need to be investigated in the future.

In addition to genes associated with cytoskeleton, motor and adhesion, several proteins involved in signaling pathways, including $G$ protein-coupled receptors, tyrosine kinases and serine/threonine kinase pathways were upregulated in male worms. Previously, several studies demonstrated that these signaling pathways were involved in the schistosome life-cycle to control growth, development, sexual differentiation, maturity and even host-parasite interactions. Thus, members of these pathways should be proposed as promising new therapeutic targets against schistosomiasis [55-58].

In the female worm, the antioxidant protein, thioredoxin domain-containing protein 4, was upregulated, which is consistent with the other studies of $S$. mansoni and S. japonicum [59-64]. Due to blood degradation in female worms, oxidative stress is generated as a by-product. Thus, higher expression of antioxidant enzymes in female worms has been proposed as a mechanism to protect against damage from oxidative stress. In $S$. mansoni, thioredoxin was not only highly upregulated in female worms but also in eggs. Thus, it has also been proposed that antioxidant mechanisms protect the embryo from oxidative damage resulting from host immunity $[59,61]$. The elastase $2 \mathrm{~b}$ was upregulated and was found among the top 50 most significantly DE transcripts in female worms. RT-qPCR of elastase $2 b$ comparing among male worms, female worms and eggs was performed and the result demonstrated that the gene was expressed the highest in female worms followed by eggs and male worms (Additional file 13: Figure S5). High expression of elastase $2 b$ in mature eggs may facilitate miracedia invade snail intermediate host as same as being required by cercariae to penetrate definitive host skin [65]. However, the real function of elastase $2 \mathrm{~b}$ in miracedia of schistosomes has not been mentioned elsewhere and need to be investigated in the future. Genes involved in glycosylation, DNAand protein-misfolding repair and gene regulation were highly enriched in female worms. These may be related to the active cell cycle, proliferation and differentiation during egg production [51].

Among the most significant GO terms in male and female upregulated transcripts, different patterns of gene expression in biological processes were revealed between male and female worms. The result showed that the majority of upregulated genes in male worms were intimately involved in the cell communication, cell signaling and cell adhesion such as delta-like protein, calcium ion binding, putative sodium/calcium exchanger, Rho GTPase-activating 


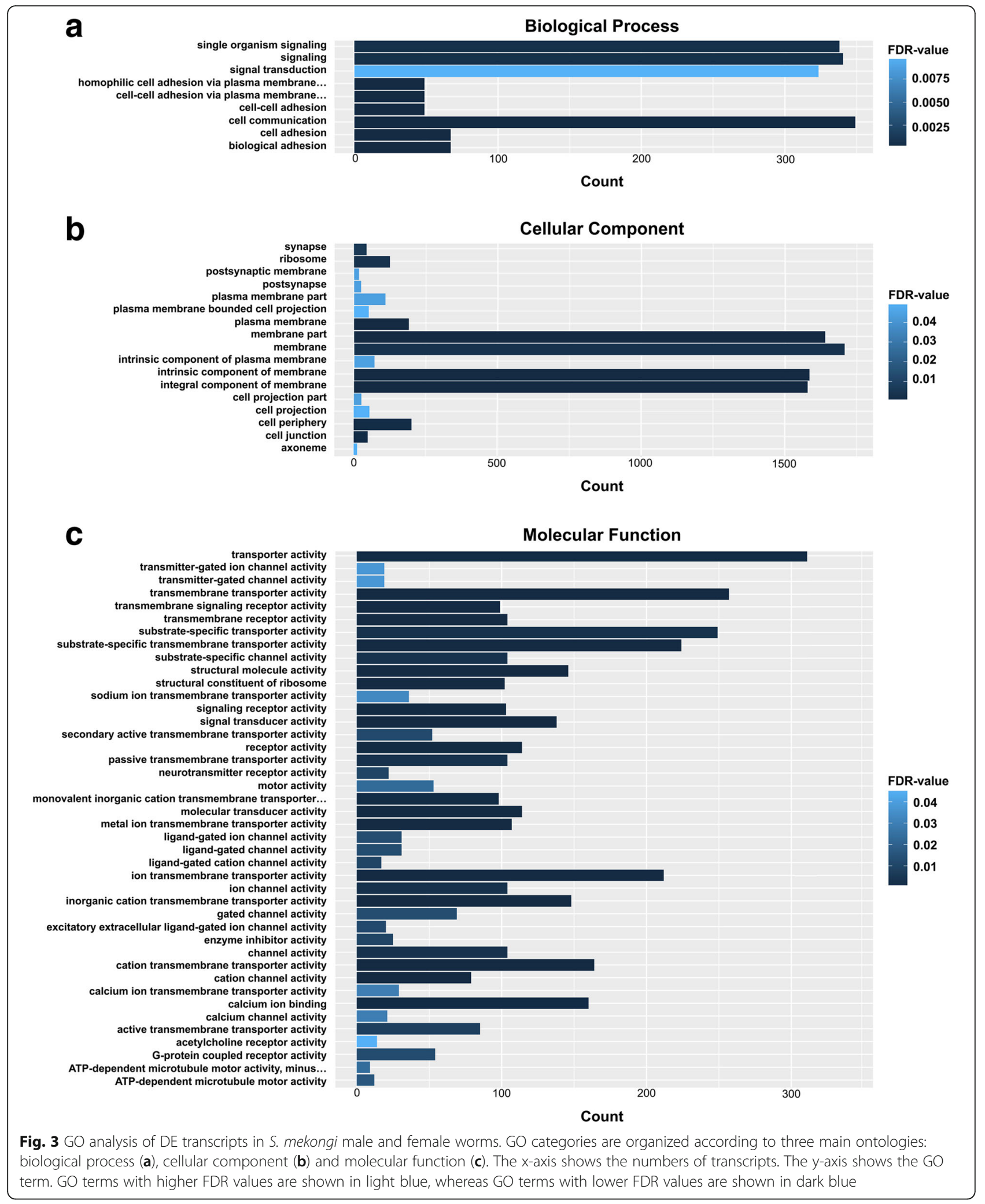

protein, G protein-coupled receptor kinase, serine/threonine-protein phosphatase, guanine nucleotide binding protein (G protein), GTP-binding protein, indicating more active host-parasite communication and interaction in male worms. In comparison, these contrasts with the upregulated genes in female worms that played roles 


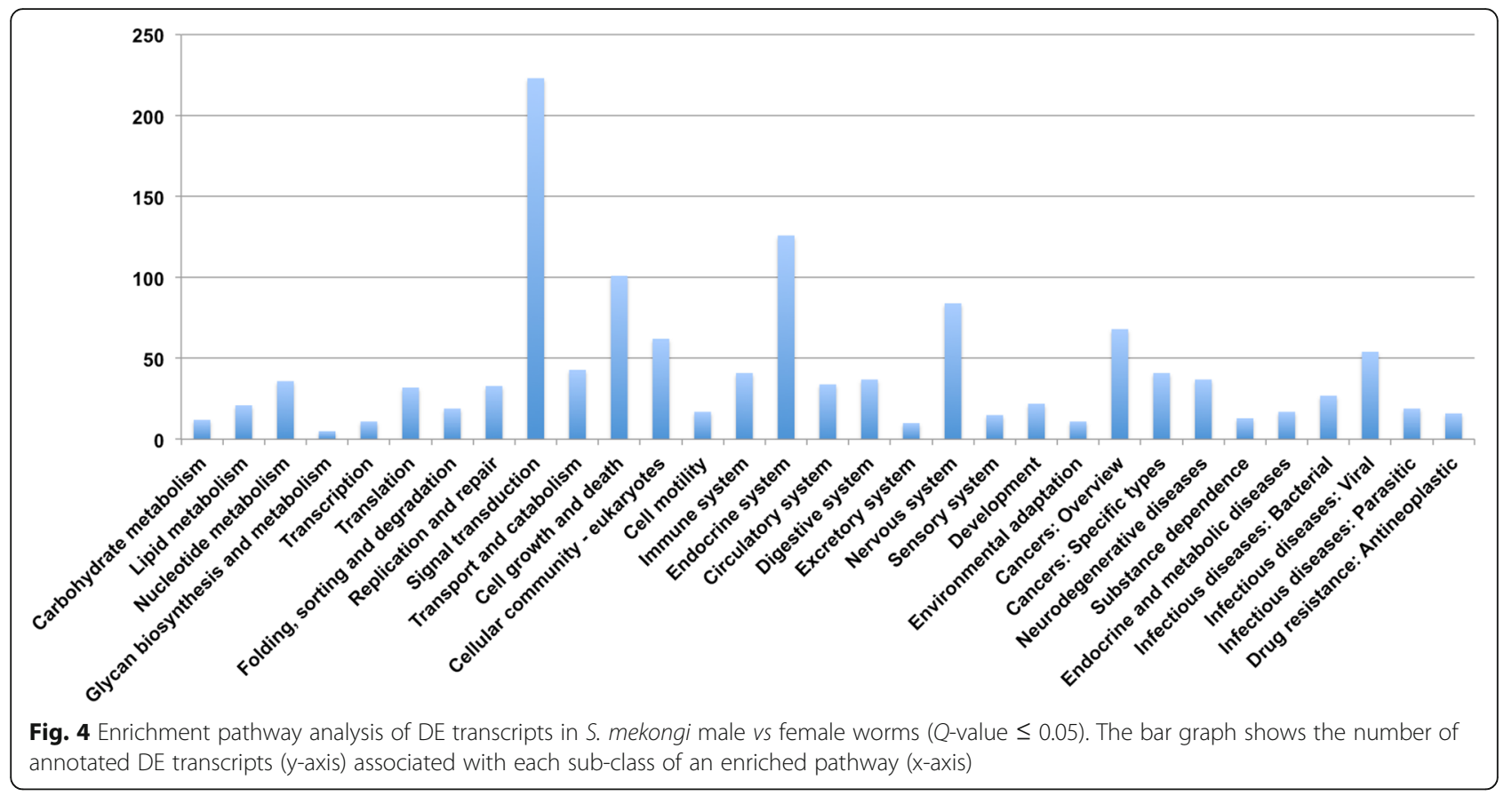

in metabolic and biosynthetic processes especially to amide and peptide, indicating that the nutritional acquisition is more crucial for female worms. This is probably reflective of its status of oviposition, which requires abundant nutrition for egg production [51].

The most significant KEGG pathway in male and female upregulated transcripts revealed that structural elements expressed differentially in the male worm included components involved in focal adhesion, regulation of the actin cytoskeleton and tight junctions. In contrast, female worms mostly upregulated genes involved in the cell cycle and meiosis specifically relating to cell division and cell differentiation, such as nipped-B protein, putative cell division cycle 20 (Cdc20) (Fizzy), cell division control protein 45-like protein, cell division cycle 7-related protein kinase, structural maintenance of chromosomes protein, family C50 non-peptidase homologue (C50 family) and the tyrosine-protein kinase $\mathrm{Abl}$. In addition, a set of genes involved in DNA replication processes, DNA polymerase, DNA helicase, putative chromosome transmission fidelity factor and putative DNA primase large subunit are preferentially expressed in the female worm. These results are presumably due to oogenesis and vitellogenesis in female worms [51, 66-68]. Moreover, we found several genes involved in the response to DNA damage or spindle abnormalities assigned to the cell cycle pathway. These included putative rad1 DNA damage checkpoint protein, putative meiotic checkpoint regulator cut 4 and putative phosphatidylinositol 3-and 4-kinase, as well as putative DNA polymerase delta small subunit and DNA polymerase III gamma-tau subunit assigned to the genetic information processing pathway (all upregulated in female worms). These observations potentially reflect cell division processes and the need to repair DNA damage caused by oxygen radicals released during the process of hemoglobin digestion, as mentioned in the previous section.

The KEGG pathway analysis revealed pathways associated with sexual differentiation and development, as well as the sex maintenance pathway for female and male worms of $S$. mekongi. These included the GnRH signaling pathway, the insulin signaling pathway and the progesteronemediated oocyte maturation pathway; these were also identified in previous studies $[40,69,70]$. Our finding that the phosphatidylinositol signaling pathway was most highly enriched was interesting. Inositol hexakisphosphate, calcium-dependent protein kinase $C$, phosphatidylinositol-4, 5-bisphosphate 3-kinase catalytic subunit alpha PI3K, diacylglycerol kinase (DAG kinase), phosphatidylinositol 4-phosphate 3-kinase $\mathrm{C} 2$ domain-containing subunit alpha and myotubularin-related protein were upregulated in male worms and inositol 1,4,5-trisphosphate receptor was specifically upregulated in female worms.

Phosphatidylinositol is a phospholipid, which is a crucial component of cellular membranes, and plays important roles in various cellular processes including growth, differentiation and vesicular secretion. The phosphatidylinositol pathway consists of a series of conversions of phosphatidylinositol into singly, doubly and triply phosphorylated forms, and has been implicated in the regulation of numerous cellular functions and responses to extracellular signals [71]. The phosphatidylinositol signaling pathway have been reported to play important roles in a multitude 


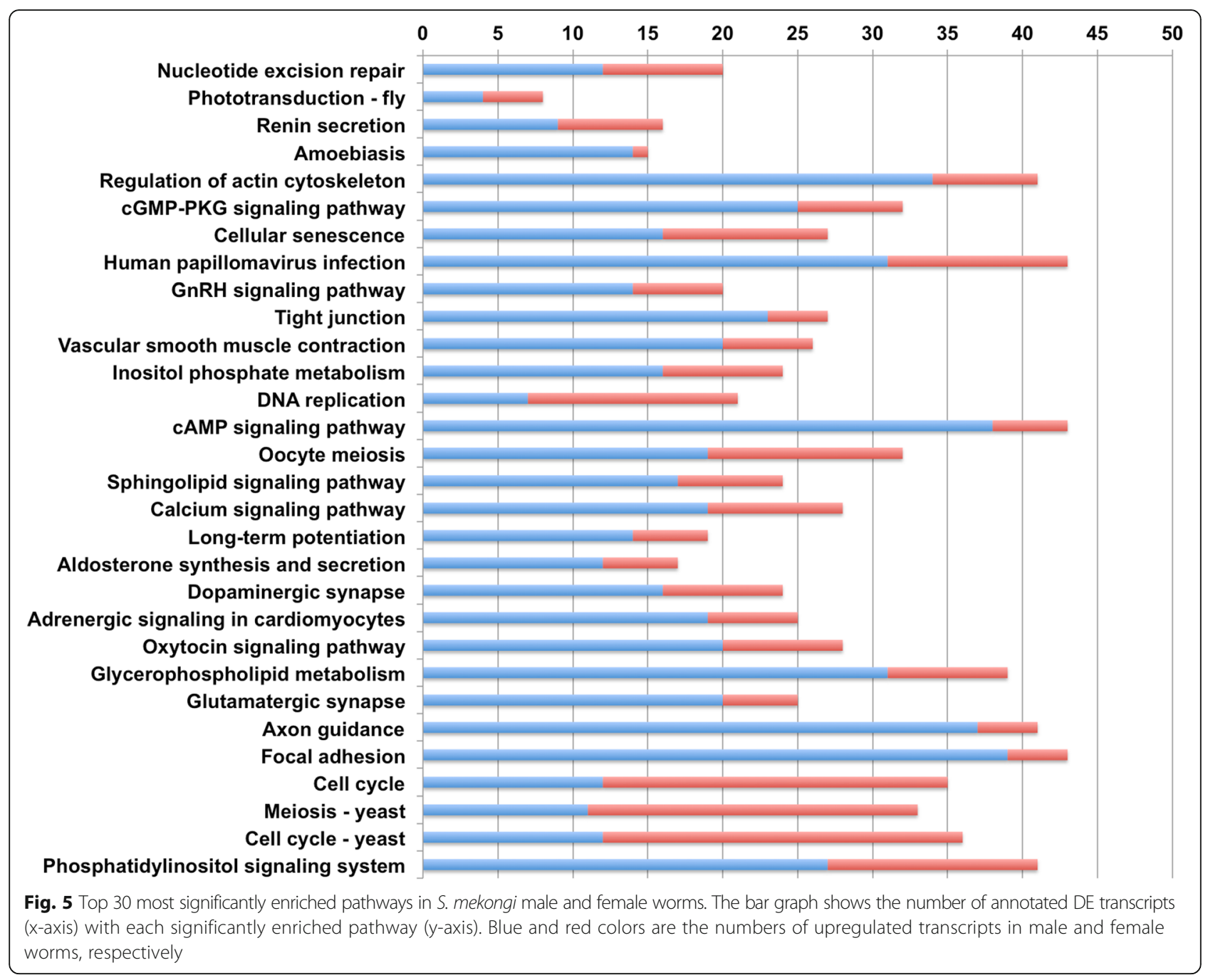

of cellular processes such as membrane trafficking, cell motility, cytoskeletal reorganization, DNA synthesis, the cell cycle, adhesion, signal transduction and reproductive systems [72, 73]. Studies of the role of the phosphatidylinositol pathway in C. elegans found that its phosphorylated forms have multiple functions; for example, phosphatidylinosito1-3-OH kinase, diacylglycerol kinase, phosphatidylinositol 4-phosphate 5-kinase and phosphatidylinositol 3-kinase, play important roles in longevity and diapause [74], thermotactic behavior [75], ovulation and fertilization [76] and the behavioral learning response [77], respectively.

In mammals, the phosphatidylinositol 3-kinase (PI3K) signal transduction pathway is necessary for seminiferous cord formation, testis and vascular development during testis morphogenesis. Inhibition of PI3K using the specific inhibitor, LY294002, blocked cord formation and impacted the number of cords and their vascular density [78, 79]. The phosphatidylinositol signaling pathway may be indispensable for $S$. mekongi survival, especially development of the male reproductive system. In the future, the functions and properties of the phosphatidylinositol signaling pathway in sex development of schistosomes need to be elucidated prior to consideration of pathway members as novel therapeutic targets against schistosomiasis.

\section{Conclusions}

In this study, we presented a transcriptomic analysis of male and female S. mekongi adult worms using RNA-Seq data. The study revealed the key biological and physiological features of male and female $S$. mekongi worms. These data will serve as a sequence resource for future studies of gene functions and will aid the ongoing whole genome sequencing efforts for $S$. mekongi, which may further facilitate the discovery of novel interventions against this persistent parasite.

\section{Methods}

Parasite materials

Adult S. mekongi worms used in this study were maintained by alternating infection of the intermediate snail 
PHOSPHATIDYLINOSITOL SIGNALING SYSTEM

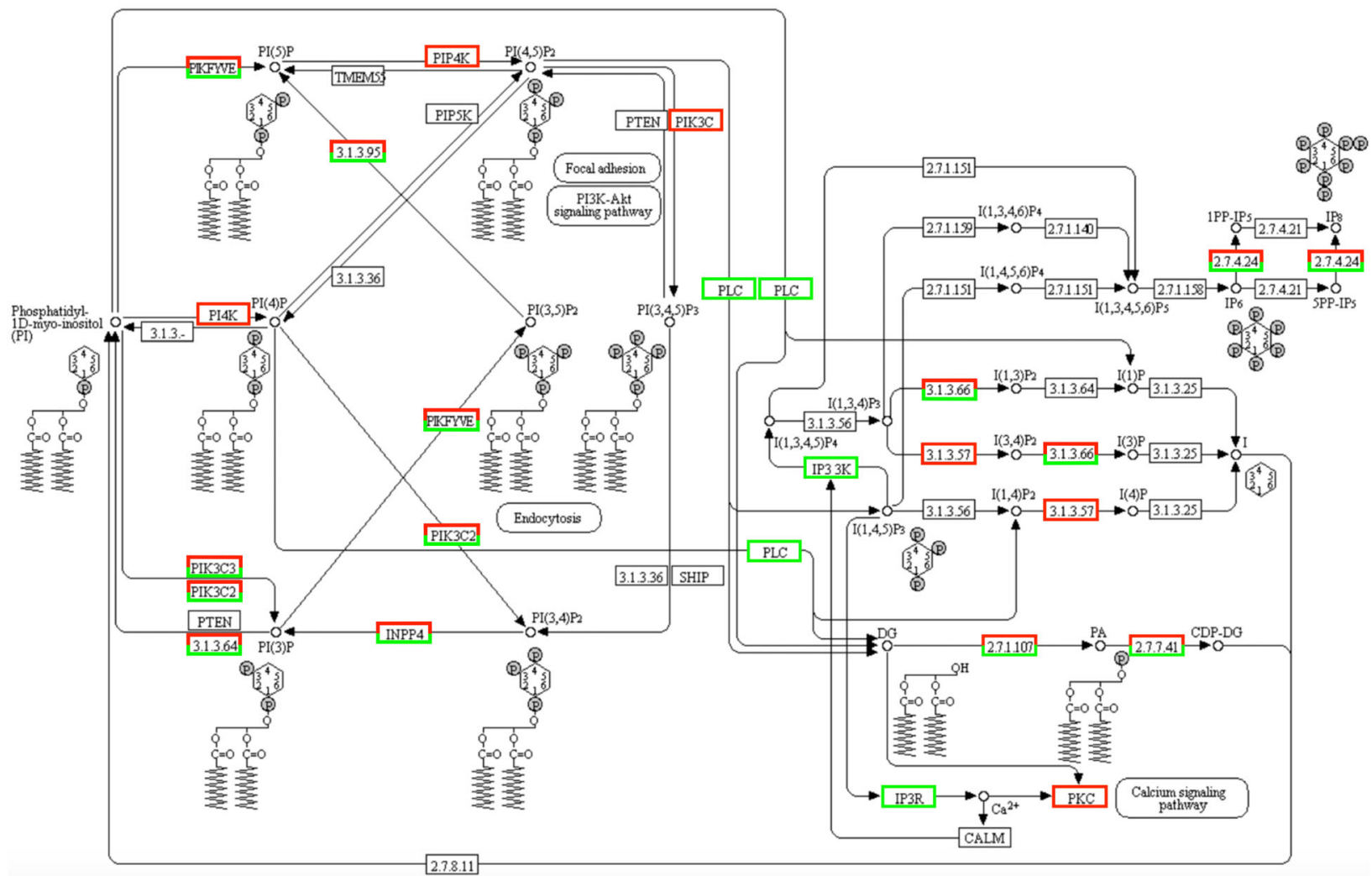

Fig. 6 Phosphatidylinositol signaling pathway. Red background indicates upregulated genes in male worms and green background indicates upregulated genes in female worms

host, $N$. aperta, and mice (Mus musculus) according to a standard protocol [80]. The $N$. aperta snails were collected from the Mekong River, Ubon Ratchathani Province, Thailand. Eight-week-old female ICR mice were purchased from the National Laboratory Animal Center, Mahidol University. Mice were infected with 25-30 cercariae by percutaneous exposure at the abdomen and then housed in the Animal Care Unit, Faculty of Tropical Medicine, Mahidol University. Eight weeks post-infection, mature adult worms were recovered from the infected mice by hepatic perfusion with $0.85 \%$ normal saline solution. Adult males and females were separated manually under a dissecting microscope. The worms were carefully washed in normal saline solution and immediately frozen at $-80^{\circ} \mathrm{C}$ until the time of RNA extraction.

\section{RNA extraction, cDNA library construction, RNA sequencing and quality control}

Total RNA was extracted from pooled adult male $(n=20)$ and female $(n=40)$ worms. Extractions for each sex were performed with three biological replicates using TRIZOL ${ }^{\mathrm{TM}}$ reagent (Invitrogen, Carlsbad, CA, USA) according to the manufacturer's instructions. RNA quantity and quality were assessed using a NanoDrop ${ }^{\circ}$ ND-1000 spectrophotometer (Thermo Fisher Scientific Inc., Wilington, DE, USA) and a 2100 Bioanalyzer (Agilent Technologies, Palo Alto, CA, USA).

For each replicate, cDNA libraries were constructed from $1 \mu \mathrm{g}$ of total RNA (Additional file 14: Figure S6) using the NEBNext ${ }^{\circ}$ Ultra ${ }^{\mathrm{TM}}$ RNA Library Prep Kit for Illumina ${ }^{\circ}$ according to the manufacturer's protocol (New England Biolabs (NEB), Ipswich, MA, USA). Briefly, mRNA isolation was performed using oligo(dT) magnetic beads contained in the NEBNext ${ }^{\circ}$ Poly(A) mRNA Magnetic Isolation Module (NEB). The mRNAs were fragmented and reverse transcribed using NEBNext ${ }^{\circ}$ First Strand Synthesis Reaction Buffer and NEBNext ${ }^{\circ}$ Random Primers. First-strand cDNA was synthesized using ProtoScript II Reverse Transcriptase and second-strand cDNA was synthesized using Second Strand Synthesis Enzyme Mix. Double-stranded cDNA was purified using the AxyPrep $^{\text {ma }}$ Mag PCR Clean-up kit (Axygen Biosciences, Union City, CA, USA) and treated with End Prep Enzyme Mix to repair both ends, add a dA-tail, and add adaptors to both ends via TA ligation. Size selection of adaptor-ligated DNA was performed using the AxyPrep $^{\mathrm{mm}}$ Mag PCR 
Clean-up kit, and fragments of $~ 360$ bp were recovered. Each sample was then amplified by PCR for 11 cycles using P5 and P7 primers; both of these primers carried sequences that can anneal to the Illumina flow cell and perform bridge PCR, and the P7 primer carried a six-base index sequence allowing for multiplexing. The PCR products were purified using the AxyPrep ${ }^{\text {tix }}$ Mag PCR Clean-up kit, analyzed using an Agilent 2100 Bioanalyzer and quantified using a Qubit 2.0 Fluorometer (Invitrogen). Barcoded libraries with different index sequences were multiplexed and loaded on an Illumina HiSeq $\mathrm{X}$ instrument according to the manufacturer's instructions (Illumina, San Diego, CA, USA). Sequencing was carried out using a $2 \times 150$ bp paired-end (PE) configuration; image analysis and base calling were conducted using the HiSeq Control Software (HCS) + RTA 2.7 (Illumina) on the HiSeq X instrument.

In order to assess sequencing quality, the raw sequencing reads were processed using the following steps. First, raw sequencing reads was assessed with FastQC software (v0.11.2) (http://www.bioinformatics.babraham. ac.uk/projects/fastqc/) to estimate read quality using PHRED quality scores. Secondly, adaptor sequences and low-quality bases (below Q30) were trimmed from the raw reads with Trimmomatic software (v.0.32) [81]. Finally, any resulting reads that were at least 50 bases long were selected for further analysis.

\section{Assembly of transcripts}

De novo assembly of clean reads was performed using the Bridger assembler [82] with either 25 or $31 \mathrm{k}$-mer sizes. The quality of each assembly was assessed using Transrate (v.1.0.3) [83] and the sequence read realignment rates for each assembly's contigs were computed with HISAT2 (v.2.0.5) [84]. In this study, the contig sequences from the assembly with $\mathrm{k}$-mer size 31 were selected for analysis due to this assembly's high realignment rate and higher N50 value. Contig sequences with coverage $>10$ reads were extracted and clustered with the CD-HIT-EST algorithm [85] to filter redundant sequences. The longest sequences from each cluster were selected as the final assembly.

\section{Annotation of transcripts}

Protein-coding sequence (CDS) regions and open reading frames (ORFs) were predicted for each assembled transcript using the TransDecoder v.5.0.1 algorithm (http:// transdecoder.github.io). The function of the predicted protein sequences was annotated using BLAST v.2.2.31 (BLASTP algorithm) [86], with searches against the UniProt Trematoda database (https://www.ncbi.nlm.nih.gov/ pmc/articles/PMC2238893/) [87]. Transcripts for which no CDS regions were predicted were subsequently analyzed with BLAST v.2.2.31 (BLASTX algorithm) [86] for alternative functional assignment. The protein family of annotated proteins was analyzed through a protein profile database (Pfam) search using HMMER3 software [88]. A threshold of $E$-value $<10^{-5}$ was applied in all the functional prediction analyses.

\section{Analysis of differentially expressed (DE) transcripts}

Trimmed sequence reads were aligned back to the assembled transcriptome using Bowtie2 (v.2.2.9) [89]. Discordant alignments were excluded. TPM (transcripts per million), FPKM (Fragments Per Kilobase Of Exon Per Million Fragments Mapped), credibility intervals and expected counts were computed using RSEM (v.1.3.0) [90]. Transcripts with expression values of more than 1 count per-million $(\mathrm{cpm})$ were extracted for differential expression analysis. Analysis of DE transcripts comparing male $v s$ female worms was conducted using edgeR v.3.20.7 [91]. The expression fold change between sexes were calculated and log-transformed. Significantly DE transcripts between sexes were extracted according to the following criteria: false discovery rate (FDR) $<0.05$ and fold change $>2.0$.

\section{Gene ontology (GO) and KEGG pathway analyses}

Significantly DE transcripts were annotated with GO terms for assignment to three major GO categories: cellular components, biological processes and molecular functions. The $\mathrm{GO}$ annotation was performed with the $\mathrm{R}$ package topGO (v.2.28.0) (https://bioconductor.org/packages/release/bioc/ html/topGO.html). Enrichment was assessed with classic Fisher's exact tests in topGO and multiple testing was done with FDR. Significant GO terms with FDR values $<0.05$ were extracted. Significantly DE transcripts were annotated with pathway information from the KEGG pathway database using the $R$ package clusterProfiler [92]. Pathway over-representation was assessed with a significance cut-off of 0.05 .

\section{Quantitative real-time polymerase chain reaction (RT-qPCR)}

A total of 10 male-associated and 10 female-associated DE transcripts, as well as 10 non-DE transcripts, were randomly selected for validation using RT-qPCR. First-strand cDNA synthesis and qPCR validation experiments were performed with three different biological replicates from the same samples used in RNA-Seq experiments. Total RNA $(1 \mu \mathrm{g})$ from each biological replicate was treated with $1 \mathrm{U}$ of DNase I (Thermo Fisher Scientific, Waltham, MA, USA) and used to synthesize first-strand cDNA using a RevertAid First Strand cDNA Synthesis kit (Thermo Fisher Scientific) according to the manufacturer's instructions. The expression level of each gene was determined by SYBR Green RT-qPCR. Each $20 \mu \mathrm{l}$ reaction mixture contained $2 \mu \mathrm{l}$ of first-strand cDNA, $1 \times$ iTaq Universal SYBR Green Supermix (Bio-Rad Laboratories, Philadelphia, PA, USA), and $300 \mathrm{nM}$ each of forward and reverse 
primers. To normalize gene expression levels, $18 \mathrm{~S}$ ribosomal RNA (rRNA) was used as an internal control $[93,94]$. Amplification was performed on a CFX96 Real-Time PCR System (Bio-Rad Laboratories, Hercules, CA, USA), according to the following protocol: pre-incubation at $95{ }^{\circ} \mathrm{C}$ for $5 \mathrm{~min}$, followed by 40 cycles of $95{ }^{\circ} \mathrm{C}$ for $20 \mathrm{~s}$ and $60{ }^{\circ} \mathrm{C}$ for $1 \mathrm{~min}$. A melting curve analysis was performed from $65-95{ }^{\circ} \mathrm{C}$. Gene expression levels were calculated using the $2^{-\Delta \Delta C t}$ method [95]. RT-qPCR experiments were performed with three replicates. Primer sequences for each target gene were designed using Primer3Plus (http://www.bioinformatics.nl/cgi-bin/primer 3plus/primer3plus.cgi) with default parameters and are listed in Additional file 15: Table S9. Correlation between RNA-Seq and qPCR results for 30 representative transcripts was analyzed using the Spearman's rank test.

\section{Additional files}

Additional file 1: Figure S1. Base quality distribution of raw reads and trimmed paired-end reads. (PDF $2840 \mathrm{~kb}$ )

Additional file 2: Table S1. Summary of raw sequencing reads, trimmed sequencing reads and sequence read assemblies. (XLSX $43 \mathrm{~kb}$ )

Additional file 3: Table S2. Detailed information on the top 50 most significantly upregulated DE transcripts. (XLSX $81 \mathrm{~kb}$ )

Additional file 4: Table S3. Detailed information on GO term analysis of DE transcripts. (XLSX $78 \mathrm{~kb}$ )

Additional file 5: Table S4. Detailed information on GO term analysis in male upregulated transcripts. (XLSX $99 \mathrm{~kb}$ )

Additional file 6: Figure S2. Bar graph for $\mathrm{GO}$ term analysis in male upregulated transcripts. (PDF $1856 \mathrm{~kb}$ )

Additional file 7: Table S5. Detailed information on GO term analysis in female upregulated transcripts. (XLSX $94 \mathrm{~kb}$ )

Additional file 8: Figure S3. Bar graph for $\mathrm{GO}$ term analysis in female upregulated transcripts. (PDF $1341 \mathrm{~kb}$ )

Additional file 9: Table S6. Detailed information on pathway analysis of DE transcripts. (XLSX $68 \mathrm{~kb}$ )

Additional file 10: Table S7. Detailed information on function of upregulated genes belonging to the phosphatidylinositol signaling pathway. (XLSX $70 \mathrm{~kb})$

Additional file 11: Table S8. Detailed information on pathway analysis in male and female upregulated transcripts. (XLSX $72 \mathrm{~kb}$ )

Additional file 12: Figure S4. Correlation between RNA-Seq and RT-qPCR results. (PDF $90 \mathrm{~kb}$ )

Additional file 13: Figure S5. Relative expression level of elastase $2 b$ in male worms, female worms and eggs. (PDF $162 \mathrm{~kb}$ )

Additional file 14: Figure S6. RNA integrity analysis. (PDF $1602 \mathrm{~kb}$ ) Additional file 15: Table S9. Oligonucleotide primer sets used for RT-qPCR validation. (PDF $58 \mathrm{~kb}$ )

\section{Abbreviations}

CDS: Coding DNA sequence; CPM: Counts per million; DE: Differentially expressed; ESTs: Expressed sequence tags; FC: Fold change; FDR: False discovery rate; FPKM: Fragments per kilobase of exon per million fragments mapped; GO: Gene ontology; KEGG: Kyoto Encyclopedia of Genes and Genomes; NGS: Next-generation sequencing; ORFs: Open reading frames; PF: Paired-end: Pfam: Protein profile database: SRA: Sequence read archive: TPM: Transcripts per million; UniProt: The Universal Protein Knowledgebase

\section{Acknowledgements}

We thank the Department of Helminthology and the Applied Malacology Laboratory, Department of Social and Environmental Medicine, Faculty of Tropical Medicine, Mahidol University for supporting all facilities and providing S. mekongi in this study, respectively. Our gratitude also goes to the Central Equipment Unit, Faculty of Tropical Medicine, Mahidol University for facilitating us all necessary instruments. We thank Edanz Group (www.edanzediting.com/ ac) for editing a draft of this manuscript.

\section{Funding}

This study was supported by FTM grant (Fiscal Year 2013) through Dr. Poom Adisakwattana, and ICTM Grants from the Faculty of Tropical Medicine, Mahidol University.

\section{Availability of data and materials}

RNA-Seq reads have been deposited in the NCBI-Sequence Read Archive (SRA) database under accession numbers SRP136896 and PRJNA445936.

Authors' contributions

OP, PAJ and PAD conceived and designed the study. OP SN and SC performed the experiments. OP, PAJ and PAD analyzed the data. OP, BES and PAD drafted the manuscript. YL, OR, SA, PD and DW helped in study design, study implementation and manuscript revision. All authors read and approved the final manuscript.

\section{Ethics approval}

All procedures performed on animals in this study were conducted following the ethical principles and guidelines for the use of animals at the National Research Council of Thailand (NRCT) and with permission from the Faculty of Tropical Medicine Animal Care and Use Committee (FTM-ACUC), Mahidol University, with approval number FTM-ACUC 014/2016.

\section{Consent for publication}

Not applicable.

\section{Competing interests}

The authors declare that they have no competing interests.

\section{Publisher's Note}

Springer Nature remains neutral with regard to jurisdictional claims in published maps and institutional affiliations.

\section{Author details}

'Department of Helminthology, Faculty of Tropical Medicine, Mahidol University, Bangkok, Thailand. ${ }^{2}$ Department of Microbiology, Faculty of Science, Mahidol University, Bangkok, Thailand. ${ }^{3}$ Department of Social and Environmental Medicine, Faculty of Tropical Medicine, Mahidol University, Bangkok, Thailand. ${ }^{4}$ Department of Molecular Tropical Medicine and Genetics, Faculty of Tropical Medicine, Mahidol University, Bangkok, Thailand. ${ }^{5}$ Department of Tropical Pathology, Faculty of Tropical Medicine, Mahidol University, Bangkok, Thailand. ${ }^{6}$ Department of Enteric Diseases, Armed Forces Research Institute of Medical Sciences, Bangkok, Thailand.

Received: 14 May 2018 Accepted: 29 August 2018

Published online: 10 September 2018

\section{References}

1. Attwood SW. Schistosomiasis in the Mekong region: epidemiology and phylogeography. Adv Parasitol. 2001;50:87-152.

2. Ross AG, Sleigh AC, Li Y, Davis GM, Williams GM, Jiang Z, et al. Schistosomiasis in the People's Republic of China: prospects and challenges for the 21st century. Clin Microbiol Rev. 2001;14:270-95.

3. Muth S, Sayasone S, Odermatt-Biays S, Phompida S, Duong S, Odermatt P. Schistosoma mekongi in Cambodia and Lao People's Democratic Republic. Adv Parasitol. 2010;72:179-203.

4. Clerinx J, Van Gompel A. Schistosomiasis in travellers and migrants. Travel Med Infect Dis. 2011:9:6-24.

5. Campa P, Develoux M, Belkadi G, Magne D, Lame C, Carayon MJ, et al. Chronic Schistosoma mekongi in a traveler-a case report and review of the literature. J Travel Med. 2014;21:361-3. 
6. Leshem E, Meltzer E, Marva E, Schwartz E. Travel-related schistosomiasis acquired in Laos. Emerg Infect Dis. 2009;15:1823-6.

7. Attwood SW. Chapter 11. Mekong schistosomiasis: where did it come from and where is it going? In: Campbell IC, editor. Aquatic Ecology, The Mekong. New York: Academic Press, Elsevier; 2009. p. 273-95.

8. Gray DJ, Ross AG, Li YS, McManus DP. Diagnosis and management of schistosomiasis. BMJ. 2011;342:d2651.

9. Wang W, Wang L, Liang Y-S. Susceptibility or resistance of praziquantel in human schistosomiasis: a review. Parasitol Res. 2012;111:1871-7.

10. Fallon PG, Doenhoff MJ. Drug-resistant schistosomiasis: resistance to praziquantel and oxamniquine induced in Schistosoma mansoni in mice is drug specific. Am J Trop Med Hyg. 1994;51:83-8.

11. King $\mathrm{CH}$, Muchiri EM, Ouma JH. Evidence against rapid emergence of praziquantel resistance in Schistosoma haematobium, Kenya. Emerg Infect Dis. 2000;6:585-94.

12. Seto EYW, Wong BK, Lu D, Zhong B. Human schistosomiasis resistance to praziquantel in China: should we be worried? Am J Trop Med Hyg. 2011:85:74-82.

13. French MD, Churcher TS, Gambhir M, Fenwick A, Webster JP, Kabatereine $N B$, et al. Observed reductions in Schistosoma mansoni transmission from large-scale administration of praziquantel in Uganda: a mathematical modelling study. PLoS Negl Trop Dis. 2010;4:e897.

14. Tebeje BM, Harvie M, You H, Loukas A, McManus DP. Schistosomiasis vaccines: where do we stand? Parasit Vectors. 2016;9:528.

15. Franco GR, Adams MD, Soares MB, Simpson AJG, Venter JC, Pena SDJ. Identification of new Schistosoma mansoni genes by the EST strategy using a directional cDNA library. Gene. 1995;152:141-7

16. Franco GR, Rabelo EM, Azevedo V, Pena HB, Ortega JM, Santos TM, et al. Evaluation of cDNA libraries from different developmental stages of Schistosoma mansoni for production of expressed sequence tags (ESTs). DNA Res. 1997;4:231-40.

17. Merrick JM, Osman A, Tsai J, Quackenbush J, LoVerde PT, Lee NH. The Schistosoma mansoni gene index: gene discovery and biology by reconstruction and analysis of expressed gene sequences. J Parasitol. 2003; 89:261-9.

18. Peng HJ, Chen XG, Wang XZ, Lun ZR. Analysis of the gene expression profile of Schistosoma japonicum cercariae by a strategy based on expressed sequence tags. Parasitol Res. 2003;90:287-93.

19. Fung MC, Lau MT, Chen XG. Expressed sequence tag (EST) analysis of a Schistosoma japonicum cercariae cDNA library. Acta Trop. 2002;82:215-24.

20. Fitzpatrick JM, Johansen MV, Johnston DA, Dunne DW, Hoffmann KF. Gender-associated gene expression in two related strains of Schistosoma japonicum. Mol Biochem Parasitol. 2004;136:191-209.

21. Fitzpatrick JM, Johnston DA, Williams GW, Williams DJ, Freeman TC, Dunne DW, et al. An oligonucleotide microarray for transcriptome analysis of Schistosoma mansoni and its application/use to investigate genderassociated gene expression. Mol Biochem Parasitol. 2005;141:1-13.

22. Fitzpatrick JM, Hoffmann KF. Dioecious Schistosoma mansoni express divergent gene repertoires regulated by pairing. Int J Parasitol. 2006;36:1081-9.

23. Moertel L, McManus DP, Piva TJ, Young L, Mclnnes RL, Gobert GN. Oligonucleotide microarray analysis of strain- and gender-associated gene expression in the human blood fluke, Schistosoma japonicum. Mol Cell Probes. 2006;20:280-9.

24. Waisberg M, Lobo FP, Cerqueira GC, Passos LK, Carvalho OS, Franco GR, et al. Microarray analysis of gene expression induced by sexual contact in Schistosoma mansoni. BMC Genomics. 2007:8:181.

25. Ojopi EP, Oliveira PS, Nunes DN, Paquola A, DeMarco R, Gregorio SP, et al. A quantitative view of the transcriptome of Schistosoma mansoni adultworms using SAGE. BMC Genomics. 2007;8:186.

26. Williams DL, Sayed AA, Bernier J, Birkeland SR, Cipriano MJ, Papa AR, et al. Profiling Schistosoma mansoni development using serial analysis of gene expression (SAGE). Exp Parasitol. 2007;117:246-58.

27. Cogswell AA, Kommer VP, Williams DL. Transcriptional analysis of a unique set of genes involved in Schistosoma mansoni female reproductive biology. PLoS Negl Trop Dis. 2012;6:e1970.

28. Rho M. New bioinformatics algorithms applied to deep sequencing projects. In: Bagnoli F, Rappuoli R, editors. Advanced Vaccine Research Methods for the Decade of Vaccines. Norfolk: Caister Academic Press. 2015. p. 33-64.

29. Chauhan P, Hansson B, Kraaijeveld K, de Knijff P, Svensson El, Wellenreuther M. De novo transcriptome of Ischnura elegans provides insights into sensory biology, colour and vision genes. BMC Genomics. 2014;15:808.
30. Liu J, Wang S, Qin T, Li N, Niu Y, Li D, et al. Whole transcriptome analysis of Penicillium digitatum strains treatmented with prochloraz reveals their drugresistant mechanisms. BMC Genomics. 2015;16:855.

31. Petrella V, Aceto S, Musacchia F, Colonna V, Robinson M, Benes V, et al. De novo assembly and sex-specific transcriptome profiling in the sand fly Phlebotomus perniciosus (Diptera, Phlebotominae), a major Old World vector of Leishmania infantum. BMC Genomics. 2015;16:847.

32. Hagel JM, Morris JS, Lee EJ, Desgagne-Penix I, Bross CD, Chang L, et al. Transcriptome analysis of 20 taxonomically related benzylisoquinoline alkaloid-producing plants. BMC Plant Biol. 2015;15:227.

33. Gu XC, Zhang YN, Kang K, Dong SL, Zhang LW. Antennal transcriptome analysis of odorant reception genes in the Red Turpentine Beetle (RTB), Dendroctonus valens. PLoS One. 2015;10:e0125159.

34. Sun J, Wang SW, Li C, Hu W, Ren YJ, Wang JQ. Transcriptome profilings of female Schistosoma japonicum reveal significant differential expression of genes after pairing. Parasitol Res. 2014;113:881-92.

35. Protasio AV, Tsai IJ, Babbage A, Nichol S, Hunt M, Aslett MA, et al. A systematically improved high quality genome and transcriptome of the human blood fluke Schistosoma mansoni. PLoS Negl Trop Dis. 2012;6:e1455.

36. Anderson L, Amaral MS, Beckedorff F, Silva LF, Dazzani B, Oliveira KC, et al. Schistosoma mansoni egg, adult male and female comparative gene expression analysis and identification of novel genes by RNA-Seq. PLoS Negl Trop Dis. 2015;9:e0004334

37. Picard MA, Boissier J, Roquis D, Grunau C, Allienne JF, Duval D, et al. Sexbiased transcriptome of Schistosoma mansoni: host-parasite interaction, genetic determinants and epigenetic regulators are associated with sexual differentiation. PLoS Negl Trop Dis. 2016;10:e0004930.

38. Wang J, Yu Y, Shen H, Qing T, Zheng Y, Li Q, et al. Dynamic transcriptomes identify biogenic amines and insect-like hormonal regulation for mediating reproduction in Schistosoma japonicum. Nat Commun. 2017;8:14693.

39. Wang $X, X u X, L u X$, Zhang Y, Pan W. Transcriptome bioinformatical analysis of vertebrate stages of Schistosoma japonicum reveals alternative splicing events. PLoS One. 2015;10:e0138470.

40. Liu GH, Xu MJ, Chang QC, Gao JF, Wang CR, Zhu XQ. De novo transcriptomic analysis of the female and male adults of the blood fluke Schistosoma turkestanicum. Parasit Vectors. 2016;9:143.

41. Almeida GT, Amaral MS, Beckedorff FC, Kitajima JP, DeMarco R, VerjovskiAlmeida S. Exploring the Schistosoma mansoni adult male transcriptome using RNA-seq. Exp Parasitol. 2012;132:22-31.

42. Lu Z, Sessler F, Holroyd N, Hahnel S, Quack T, Berriman M, et al. A gene expression atlas of adult Schistosoma mansoni and their gonads. Sci Data. 2017:4:170118.

43. Young ND, Jex AR, Li B, Liu S, Yang L, Xiong Z, et al. Whole-genome sequence of Schistosoma haematobium. Nat Genet. 2012;44:221-5.

44. Sinuon M, Tsuyuoka R, Socheat D, Odermatt P, Ohmae $H$, Matsuda $H$, et al. Control of Schistosoma mekongi in Cambodia: results of eight years of control activities in the two endemic provinces. Trans R Soc Trop Med Hyg. 2007;101:34-9.

45. Sayasone S, Utzinger J, Akkhavong K, Odermatt P. Multiparasitism and intensity of helminth infections in relation to symptoms and nutritional status among children: a cross-sectional study in southern Lao People's Democratic Republic. Acta Trop. 2015;141:322-31.

46. Vonghachack Y, Sayasone S, Khieu V, Bergquist R, van Dam GJ, Hoekstra PT, et al. Comparison of novel and standard diagnostic tools for the detection of Schistosoma mekongi infection in Lao People's Democratic Republic and Cambodia. Infect Dis Poverty. 2017;6:127.

47. Ohmae H, Sinuon M, Kirinoki M, Matsumoto J, Chigusa Y, Socheat D, et al. Schistosomiasis mekongi: from discovery to control. Parasitol Int. 2004;53:135-42.

48. Rana SB, Zadlock FJ, Zhang Z, Murphy WR, Bentivegna CS. Comparison of de novo transcriptome assemblers and k-mer strategies using the killifish, Fundulus heteroclitus. PLoS One. 2016;11:e0153104.

49. Hoffmann KF, Johnston DA, Dunne DW. Identification of Schistosoma mansoni gender-associated gene transcripts by cDNA microarray profiling. Genome Biol. 2002;3:41.

50. Piao X, Cai P, Liu S, Hou N, Hao L, Yang F, et al. Global expression analysis revealed novel gender-specific gene expression features in the blood fluke parasite Schistosoma japonicum. PLoS One. 2011;6:e18267.

51. Cai P, Liu S, Piao X, Hou N, Gobert GN, McManus DP, et al. Comprehensive transcriptome analysis of sex-biased expressed genes reveals discrete biological and physiological features of male and female Schistosoma japonicum. PLoS Negl Trop Dis. 2016;10:e0004684. 
52. Beckmann S, Quack T, Dissous C, Cailliau K, Lang G, Grevelding CG. Discovery of platyhelminth-specific alpha/beta-integrin families and evidence for their role in reproduction in Schistosoma mansoni. PLoS One. 2012;7:e52519.

53. Gelmedin V, Morel M, Hahnel S, Cailliau K, Dissous C, Grevelding CG. Evidence for integrin-venus kinase receptor 1 alliance in the ovary of Schistosoma mansoni females controlling cell survival. PLoS Pathog. 2017;13:e1006147.

54. Safaee M, Clark AJ, Ivan ME, Oh MC, Bloch O, Sun MZ, et al. CD97 is a multifunctional leukocyte receptor with distinct roles in human cancers (Review). Int J Oncol. 2013;43:1343-50.

55. Morel M, Vanderstraete M, Hahnel S, Grevelding CG, Dissous C. Receptor tyrosine kinases and schistosome reproduction: new targets for chemotherapy. Front Genet. 2014;5:238.

56. Campos TD, Young ND, Korhonen PK, Hall RS, Mangiola S, Lonie A, et al. Identification of $\mathrm{G}$ protein-coupled receptors in Schistosoma haematobium and S. mansoni by comparative genomics. Parasit Vectors. 2014;7:242.

57. Hahnel S, Wheeler N, Lu Z, Wangwiwatsin A, McVeigh P, Maule A, et al. Tissue-specific transcriptome analyses provide new insights into GPCR signalling in adult Schistosoma mansoni. PLoS Pathog. 2018;14:e1006781.

58. Walker AJ, Ressurreicao M, Rothermel R. Exploring the function of protein kinases in schistosomes: perspectives from the laboratory and from comparative genomics. Front Genet. 2014:5:229.

59. Alger HM, Sayed AA, Stadecker MJ, Williams DL. Molecular and enzymatic characterisation of Schistosoma mansoni thioredoxin. Int J Parasitol. 2002;32: 1285-92.

60. Angelucci F, Sayed AA, Williams DL, Boumis G, Brunori M, Dimastrogiovanni D, et al. Inhibition of Schistosoma mansoni thioredoxin-glutathione reductase by auranofin: structural and kinetic aspects. J Biol Chem. 2009;284:28977-85.

61. Boumis G, Angelucci F, Bellelli A, Brunori M, Dimastrogiovanni D, Miele AE. Structural and functional characterization of Schistosoma mansoni thioredoxin. Protein Sci. 2011:20:1069-76.

62. Huang HH, Day L, Cass CL, Ballou DP, Williams CH Jr, Williams DL. Investigations of the catalytic mechanism of thioredoxin glutathione reductase from Schistosoma mansoni. Biochemistry. 2011;50:5870-82.

63. Song L, Li J, Xie S, Qian C, Wang J, Zhang W, et al. Thioredoxin glutathione reductase as a novel drug target: evidence from Schistosoma japonicum. PLoS One. 2012;7:e31456.

64. Li Y, Li P, Peng Y, Wu Q, Huang F, Liu X, et al. Expression, characterization and crystal structure of thioredoxin from Schistosoma japonicum. Parasitology. 2015;142:1044-52.

65. Salter JP, Lim KC, Hansell E, Hsieh I, McKerrow JH. Schistosome invasion of human skin and degradation of dermal elastin are mediated by a single serine protease. J Biol Chem. 2000;275:38667-73.

66. Gobert GN, McManus DP, Nawaratna S, Moertel L, Mulvenna J, Jones MK. Tissue specific profiling of females of Schistosoma japonicum by integrated laser microdissection microscopy and microarray analysis. PLoS Negl Trop Dis. 2009;3: 469

67. Lu Z, Sessler F, Holroyd N, Hahnel S, Quack T, Berriman M, et al. Schistosome sex matters: a deep view into gonad-specific and pairing-dependent transcriptomes reveals a complex gender interplay. Sci Rep. 2016;6:31150

68. Kunz W. Schistosome male-female interaction: induction of germ-cell differentiation. Trends Parasitol. 2001;17:227-31.

69. You H, Zhang W, Moertel L, McManus DP, Gobert GN. Transcriptional profiles of adult male and female Schistosoma japonicum in response to insulin reveal increased expression of genes involved in growth and development. Int J Parasitol. 2009:39:1551-9.

70. You H, Gobert GN, Cai P, Mou R, Nawaratna S, Fang G, et al. Suppression of the insulin receptors in adult Schistosoma japonicum impacts on parasite growth and development: further evidence of vaccine potential. PLoS Negl Trop Dis. 2015;9:e0003730.

71. Hassan BA, Prokopenko SN, Breuer S, Zhang B, Paululat A, Bellen HJ. skittles, a Drosophila phosphatidylinositol 4-phosphate 5-kinase, is required for cell viability, germline development and bristle morphology, but not for neurotransmitter release. Genetics. 1998;150:1527-37.

72. Corvera S, D'Arrigo A, Stenmark H. Phosphoinositides in membrane traffic. Curr Opin Cell Biol. 1999;11:460-5.

73. Tawk L, Chicanne G, Dubremetz JF, Richard V, Payrastre B, Vial HJ, et al. Phosphatidylinositol 3-phosphate, an essential lipid in Plasmodium, localizes to the food vacuole membrane and the apicoplast. Eukaryot Cell. 2010;9:1519-30

74. Morris JZ, Tissenbaum HA, Ruvkun G. A phosphatidylinositol-3-OH kinase family member regulating longevity and diapause in Caenorhabditis elegans. Nature. 1996;382:536-9.
75. Biron D, Shibuya M, Gabel C, Wasserman SM, Clark DA, Brown A, et al. A diacylglycerol kinase modulates long-term thermotactic behavioral plasticity in C. elegans. Nat Neurosci. 2006;9:1499-505.

76. Xu X, Guo H, Wycuff DL, Lee M. Role of phosphatidylinositol-4-phosphate 5' kinase (ppk-1) in ovulation of Caenorhabditis elegans. Exp Cell Res. 2007;313: 2465-75.

77. Ohno H, Kato S, Naito Y, Kunitomo H, Tomioka M, lino Y. Role of synaptic phosphatidylinositol 3-kinase in a behavioral learning response in C. elegans. Science. 2014;345:313-7.

78. Uzumcu M, Westfall SD, Dirks KA, Skinner MK. Embryonic testis cord formation and mesonephric cell migration requires the phosphotidylinositol 3-kinase signaling pathway. Biol Reprod. 2002;67:1927-35.

79. Bott RC, McFee RM, Clopton DT, Toombs C, Cupp AS. Vascular endothelial growth factor and kinase domain region receptor are involved in both seminiferous cord formation and vascular development during testis morphogenesis in the rat. Biol Reprod. 2006;75:56-67.

80. Duvall RH, DeWitt WB. An improved perfusion technique for recovering adult schistosomes from laboratory animals. Am J Trop Med Hyg. 1967;16:483-6.

81. Bolger AM, Lohse M, Usadel B. Trimmomatic: a flexible trimmer for Illumina sequence data. Bioinformatics. 2014;30:2114-20.

82. Chang Z, Li G, Liu J, Zhang Y, Ashby C, Liu D, et al. Bridger: a new framework for de novo transcriptome assembly using RNA-seq data. Genome Biol. 2015;16:30

83. Smith-Unna R, Boursnell C, Patro R, Hibberd JM, Kelly S. TransRate: reference-free quality assessment of de novo transcriptome assemblies. Genome Res. 2016:26:1134-44.

84. Kim D, Langmead B, Salzberg SL. HISAT: a fast spliced aligner with low memory requirements. Nat Methods. 2015;12:357-60.

85. Li W, Godzik A. Cd-hit: A fast program for clustering and comparing large sets of protein or nucleotide sequences. Bioinformatics. 2006;22:1658-9.

86. Camacho C, Coulouris G, Avagyan V, Ma N, Papadopoulos J, Bealer K, et al. BLAST+: Architecture and applications. BMC Bioinformatics. 2009;10:421.

87. The UniProt Consortium. The Universal Protein Resource (UniProt). Nucleic Acids Res. 2007;35(Database issue):d193-7.

88. Eddy SR. Profile hidden Markov models. Bioinformatics. 1998;14:755-63.

89. Langmead B, Trapnell C, Pop M, Salzberg SL. Ultrafast and memory-efficient alignment of short DNA sequences to the human genome. Genome Biol. 2009;10:R25

90. Li B, Dewey CN. RSEM: accurate transcript quantification from RNA-Seq data with or without a reference genome. BMC Bioinformatics. 2011;12:323.

91. Robinson MD, McCarthy DJ, Smyth GK. edgeR: a Bioconductor package for differential expression analysis of digital gene expression data. Bioinformatics. 2010;26:139-40.

92. Yu G, Wang LG, Han Y, He QY. clusterProfiler: an R package for comparing biological themes among gene clusters. OMICS. 2012;16:284-7.

93. Dillon GP, Feltwell T, Skelton J, Coulson PS, Wilson RA, Ivens AC. Altered patterns of gene expression underlying the enhanced immunogenicity of radiation-attenuated schistosomes. PLoS Negl Trop Dis. 2008;2:e240.

94. Parker-Manuel SJ, Ivens AC, Dillon GP, Wilson RA. Gene expression patterns in larval Schistosoma mansoni associated with infection of the mammalian host. PLoS Negl Trop Dis. 2011;5:e1274.

95. Livak KJ, Schmittgen TD. Analysis of relative gene expression data using real-time quantitative PCR and the 2(-Delta Delta C(T)) method. Methods. 2001;25:402-8.

Ready to submit your research? Choose BMC and benefit from:

- fast, convenient online submission

- thorough peer review by experienced researchers in your field

- rapid publication on acceptance

- support for research data, including large and complex data types

- gold Open Access which fosters wider collaboration and increased citations

- maximum visibility for your research: over $100 \mathrm{M}$ website views per year

At $\mathrm{BMC}$, research is always in progress.

Learn more biomedcentral.com/submission 